\title{
Comprehensive dissection into morpho- physiologic responses, ionomic homeostasis, and transcriptomic profiling reveals the systematic resistance of allotetraploid rapeseed to salinity
}

\author{
Ying-na Feng, Jia-qian Cui, Ting Zhou, Ying Liu, Cai-peng Yue, Jin-yong Huang ${ }^{\dagger}$ and Ying-peng Hua ${ }^{*}$ (i)
}

\begin{abstract}
Background: Salinity severely inhibit crop growth, yield, and quality worldwide. Allotetraploid rapeseed (Brassica napus L.), a major glycophyte oil crop, is susceptible to salinity. Understanding the physiological and molecular strategies of rapeseed salinity resistance is a promising and cost-effective strategy for developing highly resistant cultivars.

Results: First, early leaf senescence was identified and root system growth was inhibited in rapeseed plants under severe salinity conditions. Electron microscopic analysis revealed that $200 \mathrm{mM} \mathrm{NaCl}$ induced fewer leaf trichomes and stoma, cell plasmolysis, and chloroplast degradation. Primary and secondary metabolite assays showed that salinity led to an obviously increased anthocyanin, osmoregulatory substances, abscisic acid, jasmonic acid, pectin, cellulose, reactive oxygen species, and antioxidant activity, and resulted in markedly decreased photosynthetic pigments, indoleacetic acid, cytokinin, gibberellin, and lignin. ICP-MS assisted ionomics showed that salinity significantly constrained the absorption of essential elements, including the nitrogen, phosphorus, potassium, calcium, magnesium, iron, mangnese, copper, zinc, and boron nutrients, and induced the increase in the sodium/ potassium ratio. Genome-wide transcriptomics revealed that the differentially expressed genes were involved mainly in photosynthesis, stimulus response, hormone signal biosynthesis/transduction, and nutrient transport under salinity.

Conclusions: The high-resolution salt-responsive gene expression profiling helped the efficient characterization of central members regulating plant salinity resistance. These findings might enhance integrated comprehensive understanding of the morpho-physiologic and molecular responses to salinity and provide elite genetic resources for the genetic modification of salinity-resistant crop species.
\end{abstract}

Keywords: Allotetraploid rapeseed, Differential gene expression, Ion homeostasis, Morpho-physiologic response, Salinity resistance

\footnotetext{
* Correspondence: yingpenghua@zzu.edu.cn

${ }^{\dagger}$ Jin-yong Huang and Ying-peng Hua contributed equally to this work. School of Agricultural Sciences, Zhengzhou University, Zhengzhou 450001, China
}

(c) The Author(s). 2020 Open Access This article is licensed under a Creative Commons Attribution 4.0 International License, which permits use, sharing, adaptation, distribution and reproduction in any medium or format, as long as you give appropriate credit to the original author(s) and the source, provide a link to the Creative Commons licence, and indicate if changes were made. The images or other third party material in this article are included in the article's Creative Commons licence, unless indicated otherwise in a credit line to the material. If material is not included in the article's Creative Commons licence and your intended use is not permitted by statutory regulation or exceeds the permitted use, you will need to obtain permission directly from the copyright holder. To view a copy of this licence, visit http://creativecommons.org/licenses/by/4.0/. The Creative Commons Public Domain Dedication waiver (http://creativecommons.org/publicdomain/zero/1.0/) applies to the data made available in this article, unless otherwise stated in a credit line to the data. 


\section{Background}

Soil salinization is a serious limiting factor worldwide for high productivity and high quality of agriculture crops $[1,2]$. Approximately $50 \%$ of arable lands are thought to be detrimentally affected by salinity, and this proportion is estimated to increase continuously, due to the emergence of global extreme climate and overuse of hypersaline irrigation water [3-5]. Soil salinity inhibits crop growth and development, which in turn reduces yield production, through a two-phase physiological dysfunction: (i) osmotic stresses that declines water potential and (ii) ion toxicity that disturbs ion homeostasis [6]. These stresses are associated with the disorder of a variety of biological processes, including cellular homeostasis imbalance, oxidative stress, essential nutrient dysfunction, protein synthesis disruption, retarded organ growth, and even plant death [7].

In higher plants, maintaining a low $\mathrm{Na}^{+}$level and a suitable range of $\mathrm{K}^{+} / \mathrm{Na}^{+}$ratios in cells is necessary to enhance plant salinity resistance $[6,8]$. Overaccumulation of excessive $\mathrm{Na}^{+}$in the cytoplasm is prevented using three main strategies in plants: (i) inhibiting $\mathrm{Na}^{+}$influx into cytoplasma, (ii) elevating $\mathrm{Na}^{+}$sequestration into vacuoles, and (iii) enhancing $\mathrm{Na}^{+}$efflux from intracellular parts $[9,10]$. Under salinity stress, some nonselective cation channels (NSCCs), $\mathrm{K}^{+}$permeases, and other type transporters allow $\mathrm{Na}^{+}$influx into plant cells [11]. Thus, maintaining a suitable ion homeostasis is an important strategy for the resistance of plants to salinity. Salt Overly Sensitive (SOS) signaling pathways and nonselective cation channels (NSCCS) are key to the regulation of root $\mathrm{Na}^{+}$influx and efflux $[12,13] . \mathrm{Na}^{+} / \mathrm{H}^{+}$antiporters (NHXs) mediate the transport of $\mathrm{Na}^{+}$into the vacuole, and contribute to vacuolar $\mathrm{Na}^{+}$compartmentation that is crucial for the plant SSR. Besides, enhancing the biosynthesis of compatible osmolytes, antioxidants, and polyamines, and maintaining homeostasis of reactive oxygen species (ROS) and phytohormones are also pivotal strategies for plants resistant to salinity stress [14].

Allotetraploid rapeseed (Brassica napus L.) is widely used for production of edible vegetable oil, livestock protein meal, and industrial biodiesel [15]. The allotetraploid rapeseed $\left(A_{n} A_{n} C_{n} C_{n}, \sim 1345 \mathrm{Mb}, 2 n=4 x=38\right)$ is derived from its diploid progenitors $B$. rapa $\left(\mathrm{A}_{\mathrm{r}} \mathrm{A}_{\mathrm{r}}\right.$, $485 \mathrm{Mb}, 2 n=2 x=20)$ [16] and B. oleracea $\left(\mathrm{C}_{\mathrm{o}} \mathrm{C}_{\mathrm{o}}, \sim 630\right.$ $\mathrm{Mb}, 2 n=2 x=18$ ) [17-19]). The rapeseed genome contains numerous duplicated chromosomal segments and homeologous genomic regions, further resulting in polygenic family formation $[18,20]$.

Salinity greatly hinders the rapeseed biomass and seed yield [20]. Despite various publications on the improvement of rapeseed salinity resistance, limited progress has been made in this direction [21-23]. A comprehensive understanding of the morpho-physiologic and molecular mechanisms underlying the salinity resistance may facilitate the improvement in crop performance under salinity. Breeding and deployment of the salt-resistant rapeseed genotypes having good performance can be an appropriate solution to maintain an optimal yield under salinity [24]. Morpho-physiologic responses of rapeseed plants to salinity were identified and genome-wide transcriptional profile of rapeseed seedlings in response to salinity was investigated in the present study. This study might enrich understanding of the morpho-physiological strategies involving the resistance of rapeseed to salinity, and the identification of core salt-responsive differentially expressed genes (DEGs) might provide elite genetic resources for molecular breeding of salinity-resistant rapeseed germplasm.

\section{Results}

\section{Morphologic responses of oilseed rape to salinity}

Rapeseed plants were grown in hydroponic solution under 0 (control), $50 \mathrm{mM}, 100 \mathrm{mM}, 150 \mathrm{mM}, 200 \mathrm{mM}$, and $250 \mathrm{mM} \mathrm{NaCl}$ conditions to select the most suitable $\mathrm{NaCl}$ concentrations for the rapeseed salinity resistance study. Compared with the control condition, the rapeseed plants started to show obvious growth retardation, including leaf necrosis and root inhibition, when the $\mathrm{NaCl}$ concentrations were higher than $100 \mathrm{mM}$ (Fig. 1a, b). The salinity-induced growth repression was also indicated by a significant decrease in the shoot and root biomasses (Fig. 1c). The reduction in the shoot and root dry weight was up to $50 \%$ with $200 \mathrm{mM} \mathrm{NaCl}$ (Fig. 1c), which was used in the following salinity experiments and was also widely applied in previous studies [25].

In this study, no significant changes were observed in the root/shoot ratio with $200 \mathrm{mM} \mathrm{NaCl}$ (Fig. 1d). Subsequently, the specific effect of salinity on the shoot and root growth was determined (Fig. 1e-h). Salinity caused a decrease of $40 \%$ in total leaf areas (Fig. 1e). However, specific leaf weight was doubled under salinity (Fig. 1f), indicating a marked increase in the leaf thickness. On the contrary, salinity led to a significant reduction in various root system architecture-related parameters, including the maximum length (Fig. 1g), total length, volume, surface area, and average diameter (Fig. 1h).

A scanning electron microscope was used to observe trichome and stoma morphology of young leaf epidermis and transmission electron microscope was used to identify organelle damages, so as to examine the intracellular ultrastructure underlying the morphological differences under the control and salt conditions (Fig. 2). The number of leaf trichomes significantly was reduced under salinity compared with the control condition (Fig. 2a, b). However, the overall morphology and surface mastoids of the leaf trichomes were not significantly altered under the control and salinity conditions (Fig. 2c, f). The stoma 


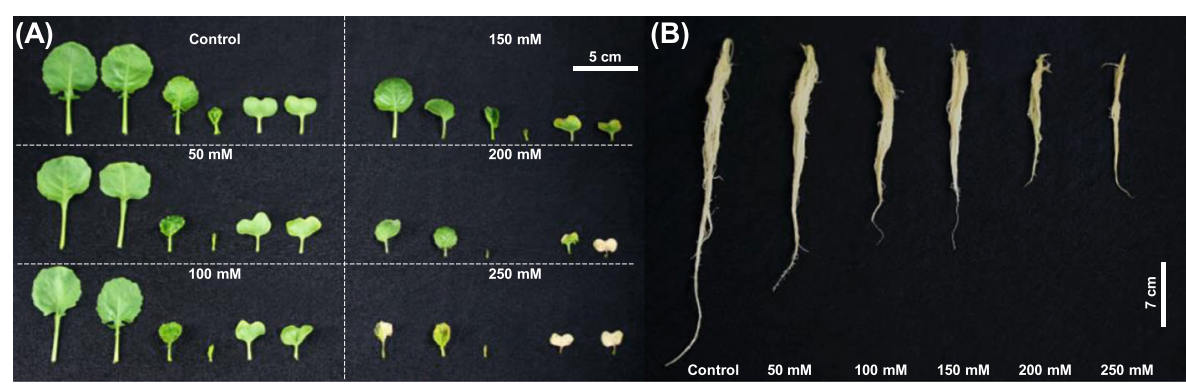

(C)
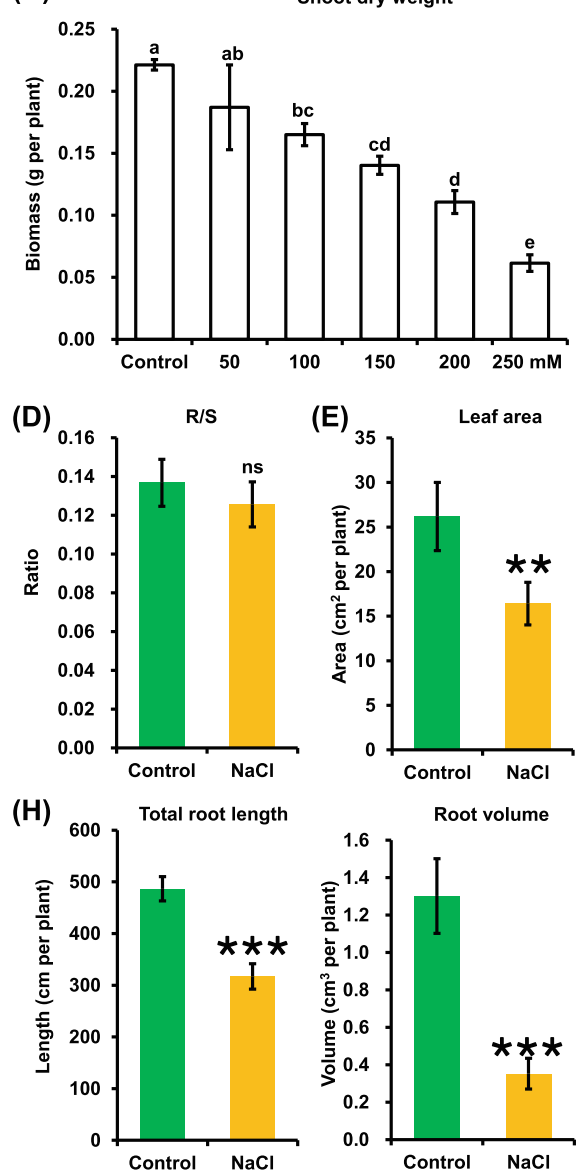
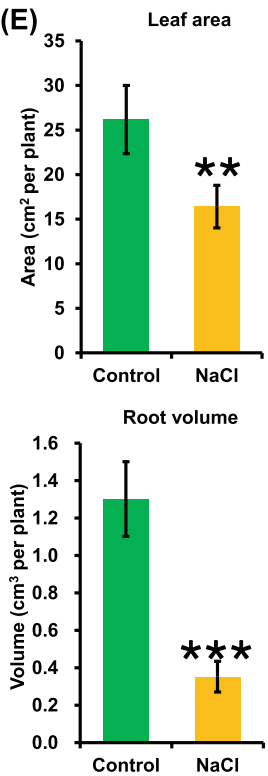
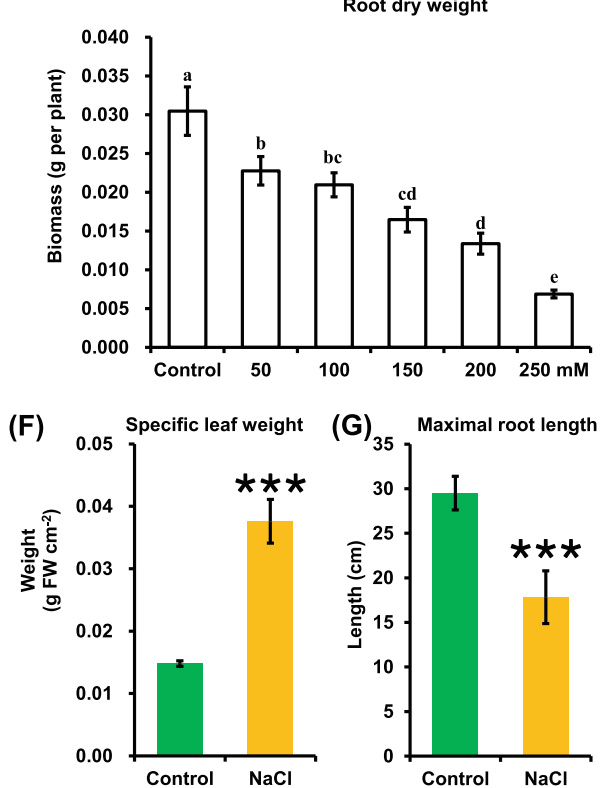

(G) 35 Maximal root length
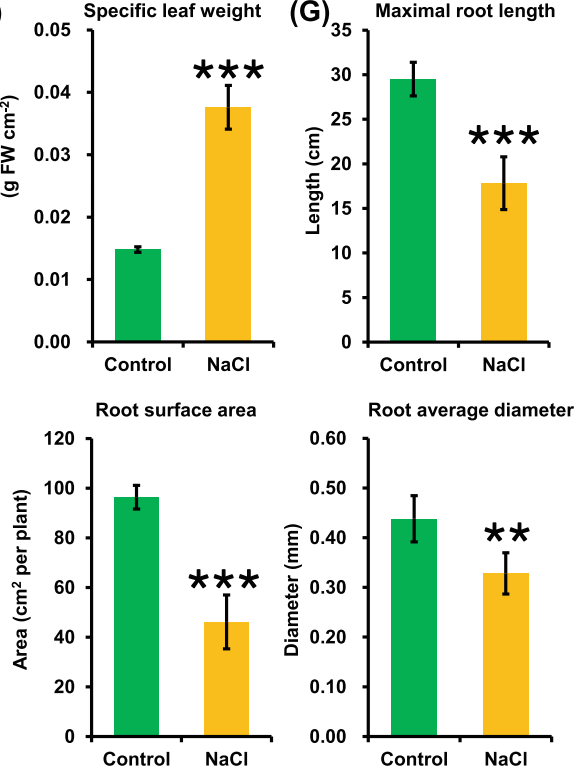

Fig. 1 Growth performance of rapeseed plants under the control and salinity conditions. (A-B) Growth performance of the shoots (a) and roots (b) in rapeseed plants under different dosages of salt conditions. c Shoot and root dry weight of the rapeseed plants under different NaCl concentrations. The uniform rapeseed plants after 7-day seed germination were grown under NaCl-free (control) for 10 days, and then were changed to the solution containing $0-250 \mathrm{mM} \mathrm{NaCl}$ for 5 days. Different lowercases indicate the significant differences at $P<0.05$. (D-H) Root/ shoot $(\mathrm{R} / \mathrm{S})$ ratio $(\mathbf{d})$, leaf area $(\mathbf{e})$, specific leaf weight (f), maximal root length $(\mathbf{g})$, and root system architecture (h) under control and $200 \mathrm{mM}$ $\mathrm{NaCl}$ conditions. For $\mathbf{d}-\mathbf{h}$, uniform rapeseed plants after 7-day seed germination were grown under $\mathrm{NaCl}$-free (control) for 10 days, and then they were transferred to the solution containing $200 \mathrm{mM} \mathrm{NaCl}$ for 5 day. Data are means $( \pm \mathrm{SD}), n=5$. ns, not significant; ${ }^{*}, P<0.05$; ${ }^{* *}, P<0.01$; ***, $P<0.001$

number obviously reduced under salinity than under the control condition (Fig. $2 \mathrm{~g}$ and $\mathrm{h}$ ). In addition, the wax coat of leaf surface was found to be larger under salinity than under the control condition (Fig. 2i, j). Moreover, the stoma showed a higher closure degree under salinity than under the control condition (Fig. 2k, l). The number of starch granules in the chloroplasts markedly decreased under salinity, which also resulted in detached cells and shrunken plasma membranes, namely plasmolysis (Fig. 2m, p).

\section{Physiological responses of rapeseed plants to salinity}

Based on the differential morphologic analysis between the control and salinity conditions, the salinity-induced 


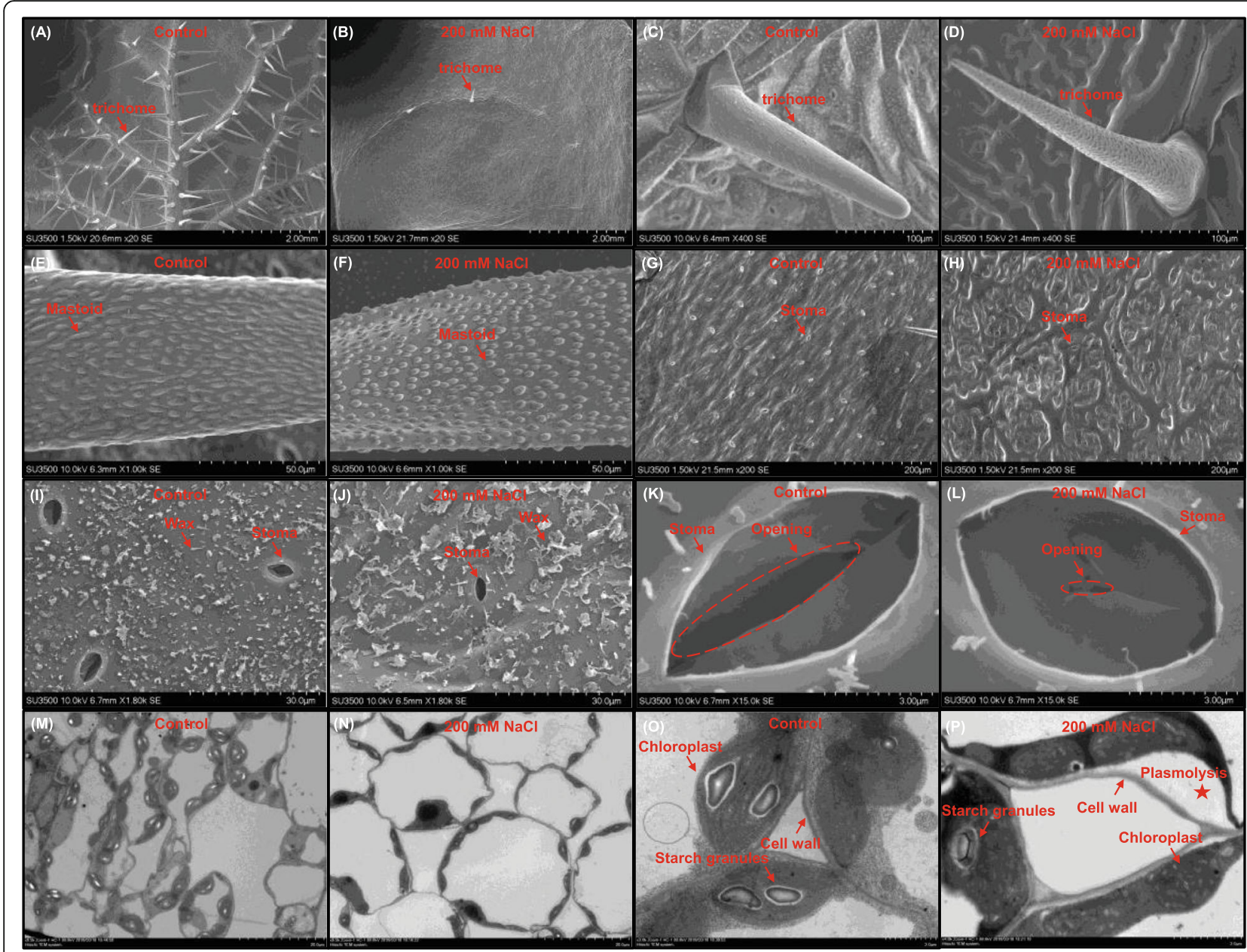

Fig. 2 Microscopy characterization of leaf ultrastructure of rapeseed plants under the control and salt conditions. a-d Low-magnification view (a, b) and close-up images $(\mathbf{c}, \mathbf{d})$ of leaf trichomes. (e-f) Mastoid morphology on the surface of trichomes. $\mathbf{g}$-j Low-magnification view (g, h) and morphology of wax coats on leaf surfaces $(\mathbf{i}, \mathbf{j})$. $\mathbf{k}$-I Close-up images of stoma. $\mathbf{m}$-p Low-magnification $(\mathbf{m}, \mathbf{n})$ and close-up $(\mathbf{o}, \mathbf{p})$ view of chloroplasts along plasma membranes and cell morphologies. Uniform rapeseed plants after 7-day seed germination were cultivated under $\mathrm{NaCl}$ free (control) for 10 days, and then they were transferred to the solution containing $200 \mathrm{mM} \mathrm{NaCl}$ for 5 days. The trichomes, mastoids, stoma, cell walls, chloroplasts, and starch granules are indicated by arrows, and the plasmolysis is denoted by an asterisk. The opening of the stoma is indicated by dashed circles

physiologic changes were further explored in rapeseed plants. The results showed a negative effect of salinity on the net photosynthesis rate, which was reduced by more than 20\% (Fig. 3a). Besides the reduction in stoma number and conductance identified by scanning microscopy under salinity (Fig. 2a, d), stomatal conductance was reduced by more than a half (Fig. 3a). The decreased stomatal conductance was related to the reduction in the intracellular $\mathrm{CO}_{2}$ concentrations, which was approximately reduced by a quarter (Fig. 3a). In addition, the transpiration rate of the rapeseed plants was obviously lower under salinity than under the control condition (Fig. 3a).

The assay of SPAD values, representing leaf chlorophyll contents, also showed that salinity inhibited the photosynthesis of rapeseed plants (Fig. 3b). Further, the effect of salinity on photosynthetic pigments was investigated. Without exception, the concentrations of both total chlorophylls (including chlorophyll a and b) and carotenoids (including xanthophyll and carotene) were significantly reduced (Fig. 3c). The concentration ratio of chlorophyll $a$ to chlorophyll $b$ was obviously higher under salinity than that under the control condition (Fig. 3d). In addition, salinity reduced the ratio of total chlorophyll concentration to carotenoid concentration (Fig. 3d). Overaccumulated anthocyanin was also observed, which was validated by its significantly increased concentrations under salinity (Fig. 3e).

Some key metabolites that might be involved in the SSR regulation were tested to further understand the physiological responses of rapeseed plants to salinity. The concentrations of soluble proteins, proline, 


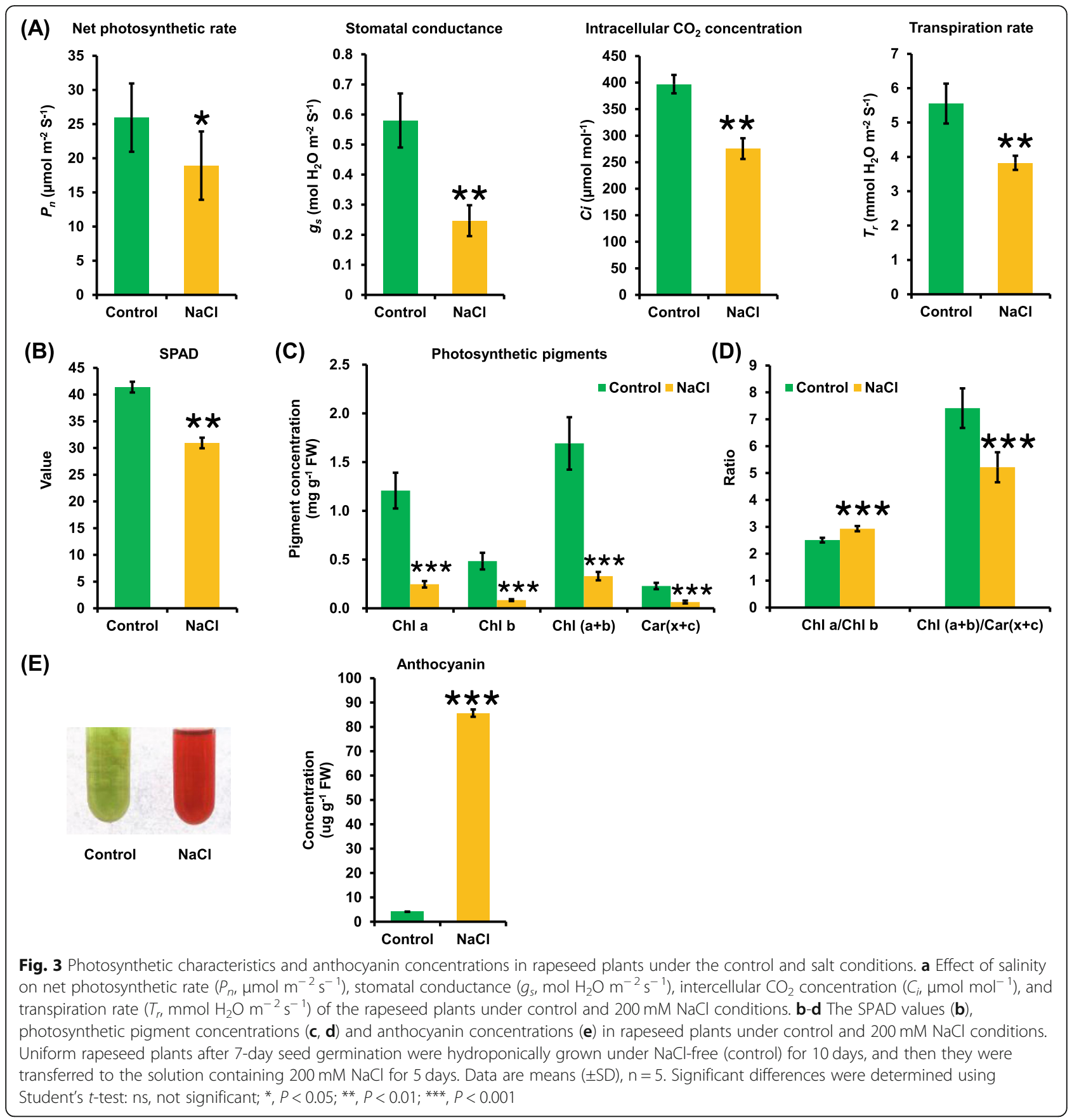

malondialdehyde (MDA), and soluble sugar were significantly increased in the shoots and roots of rapeseed plants after exposure to salinity (Fig. 4a). In this study, no significant changes in the betaine concentrations were observed in both shoots and roots of the rapeseed plants under salinity compared with the control condition (Fig. 4a). Subsequently, phytohormone responses of rapeseed plants under salinity were investigated. In general, the concentrations of indoleacetic acid (IAA), cytokinin (CTK), and gibberellic acid (GA) were significantly lower under salinity than under the control condition in the rapeseed plants (Fig. 4b). However, the GA concentrations in the shoots showed no significant differences between the control and salinity conditions (Fig. 4b). On the contrary, the concentrations of abscisic acid (ABA) and jasmonic acid (JA) in the shoots and roots were significantly higher under salinity compared with the control condition (Fig. 4b).

Cell wall components were measured because the curl and changes in the cell wall ultrastructure were observed 


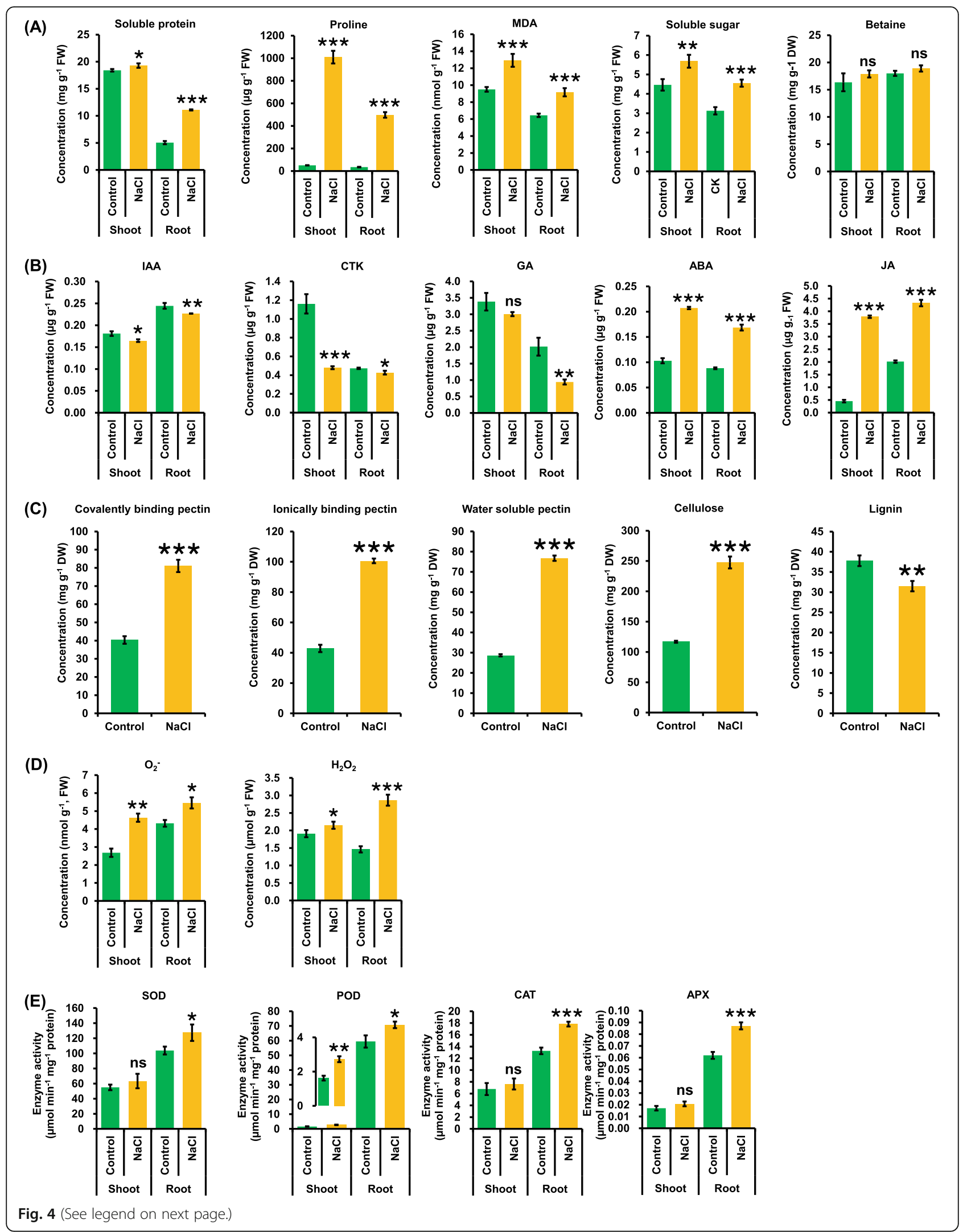


(See figure on previous page.)

Fig. 4 Some key metabolite profiling of rapeseed plants under the control and salt conditions. a-e Concentrations of some osmoregulation substances ( $A$, including soluble protein, proline, MDA, soluble sugar and betaine), phytohormones (B, including IAA, CTK, GA, ABA, and JA), cell wall components (c, including covalently/ionically binding and water soluble pectin, cellulose, and lignin), reactive oxygen species (d, including $\mathrm{O}_{2}{ }^{-}$and $\mathrm{H}_{2} \mathrm{O}_{2}$ ) and the activity of antioxidant enzymes (e, SOD, POD, CAT, and APX) in the shoots and roots of the rapeseed plants under control and $200 \mathrm{mM} \mathrm{NaCl}$ conditions. Uniform rapeseed plants after 7-day seed germination were hydroponically grown under $\mathrm{NaCl}$-free (control) for 10 days, and then they were transferred to the solution containing $200 \mathrm{mM} \mathrm{NaCl}$ for 5 days. Data are means $( \pm \mathrm{SD}), n=3$. ns, not significant; ${ }^{*}, P<0.05 ;{ }^{* *}$, $P<0.01 ; * *, P<0.001$

in the rapeseed leaves under salinity. Responses of covalently/ionically binding and water-soluble pectin, cellulose, and lignin to salinity are plotted in Fig. 4c. Compared with the control condition, the concentrations of covalent/ionic binding and water-soluble pectin, and cellulose in the shoots were about two-folds of those under the control condition (Fig. 4c). However, the lignin concentration was significantly decreased under salinity (Fig. 4c). The disorder of cell wall structure usually induces electrolyte leakage, which was often accompanied by ROS accumulation [26]. The superoxide anion $\left(\mathrm{O}_{2}{ }^{-}\right)$and hydrogen peroxide $\left(\mathrm{H}_{2} \mathrm{O}_{2}\right)$ concentrations in the shoots and roots were significantly higher under salinity than that under the control condition (Fig. 4d). The ROS homeostasis is governed by a complicated regulation in ROS production and scavenging. The result showed that more ROS were accumulated under salinity than under the control condition (Fig. 4d). In response to salinity, the activities of superoxide dismutase (SOD), peroxidase (POD), catalase (CAT), and ascorbate peroxidase (APX) were significantly increased in the plant roots. However, the activities of SOD, CAT, and APX were not significantly altered in the shoots except that the POD activity was obviously elevated (Fig. 4e).

\section{Ionomic responses of rapeseed plants to salinity}

Subsequently, ICP-MS was used to assay the ionomic profiling between the control and salinity conditions. The results showed that most of the concentrations of mineral elements, including some macronutrients $(\mathrm{N}, \mathrm{P}$, $\mathrm{K}, \mathrm{Ca}$, and $\mathrm{Mg}$ ) and micronutrients $(\mathrm{Fe}, \mathrm{Cu}, \mathrm{Mn}, \mathrm{Zn}$, and $\mathrm{B})$, in the shoots and roots were obviously deceased under salinity compared with the control condition (Fig. 5a-p). Quantitative analysis by ICP-MS showed that $\mathrm{Na}^{+}$concentrations were significantly increased in both shoots and roots under salinity (Fig. $5 \mathrm{~d}$ ). Moreover, the $\mathrm{Na}^{+}$concentration in the shoots was higher than that in the roots (Fig. 5d). The $\mathrm{Na}^{+}$concentration in the roots, hypocotyls, petioles, and leaf blades was measured in this study to further characterize the distribution of $\mathrm{Na}^{+}$into plants. The analysis showed that the $\mathrm{Na}^{+}$concentration was the highest in the petioles, followed by that in the leaf blades and in the roots, and the lowest in hypocotyls (Fig. 5e). The translocation factor of $\mathrm{Na}^{+}$was significantly increased under salinity than that under the control condition (Fig. 5f). Under salinity, the $\mathrm{Na}^{+} / \mathrm{K}^{+}$ ratio was remarkably increased in both the shoots and roots (Fig. 5g). Biomass comparison analysis showed that the accumulation of $\mathrm{Na}^{+}$resulted in a higher decrease in the biomass of shoots than that of roots (Fig. $5 \mathrm{~h}$ ).

Subsequently, the concentrations of some other metal cations, including $\mathrm{Ca}^{2+}, \mathrm{Fe}^{2+}, \mathrm{Cu}^{2+}, \mathrm{Mg}^{2+}, \mathrm{Mn}^{2+}$, and $\mathrm{Zn}^{2+}$, and a metalloid nutrient, namely B, were examined (Fig. 5i-p). In general, the $\mathrm{Ca}^{2+}, \mathrm{Fe}^{2+}$, and $\mathrm{Cu}^{2+}$ showed a similar response pattern under salinity. In detail, the concentrations of $\mathrm{Ca}^{2+}, \mathrm{Fe}^{2+}$, and $\mathrm{Cu}^{2+}$ in the shoots were significantly decreased; on the contrary, their concentrations were obviously increased in the roots (Fig. 5i-l). The $\mathrm{Mg}^{2+}$ and $\mathrm{Mn}^{2+}$ concentrations in both the shoots and roots were significantly decreased under salinity (Fig. $5 \mathrm{~m}$ and $\mathrm{n}$ ). Different from the abovementioned cations, the $\mathrm{Zn}^{2+}$ concentrations in both the shoots and roots did not significantly change under salinity compared with the control condition (Fig. 50). Also, the B concentrations in the shoots and roots were significantly lower under salinity than those under the control condition (Fig. 5p).

\section{Genome-wide transcriptional responses of rapeseed plants to salinity}

After removing adapter sequences and low-quality reads, approximately $5.4 \times 10^{7}$ clean reads of each sample were obtained. Total length of clean reads of 12 samples reached about $6.5 \times 10^{8}$ nt with $\mathrm{Q}_{20}>98 \%$ and $\mathrm{Q}_{30}>95 \%$ (Supplementary Table S1). Most of Pearson correlation coefficients between each pair of biological replicates under the same treatment were higher than 0.90 (Supplementary Fig. S1), indicating that the transcriptome data were highly credible.

Subsequently, global differential gene expression of rapeseed was detected under $200 \mathrm{mM} \mathrm{NaCl}$ condition compared with the salt-free condition. First, 10 DEGs were selected to compare their expression consistency between the RT-qPCR assays and transcriptome sequencing. The results showed that most of the gene expression was highly correlated $(r>0.95)$ between the two assays (Fig. 6a). The principal component analysis revealed significant differences in the expression patterns between different treatments and different rapeseed tissues (Fig. 6b). A total of 13,107 and 14,203 genes were 


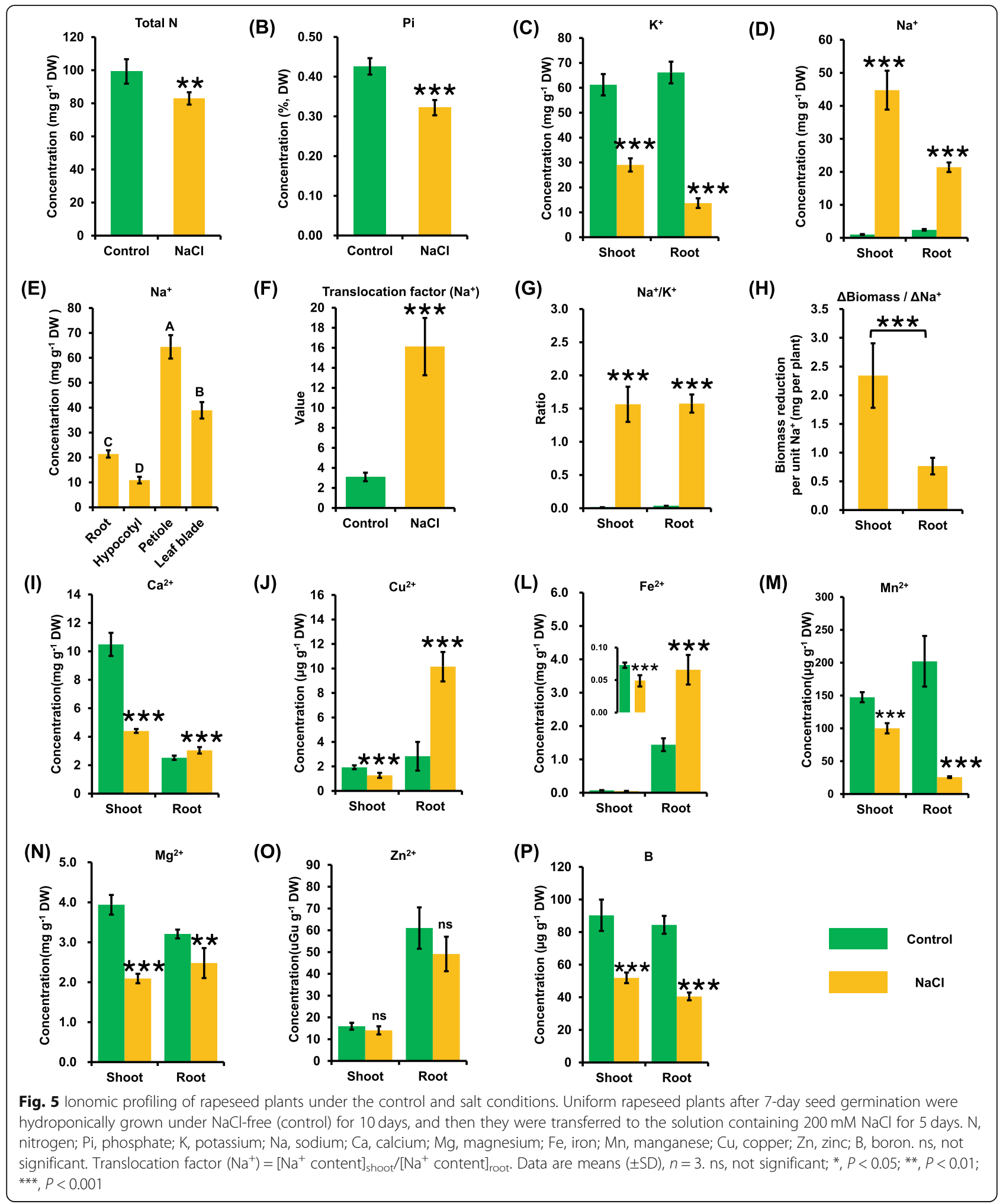

identified to be differentially expressed in the shoots and roots under salinity, respectively (Fig. 6c). The number of downregulated DEGs in both the shoots and roots was larger than that of upregulated DEGs (Fig. 6c).
Further, the effect of salinity on the homeolog expression bias was surveyed between the An and Cn subgenomes of allotetraploid rapeseed (Fig. 6d, e). In general, the DEGs on the $\mathrm{Cn}$ subgenomes were more abundant 


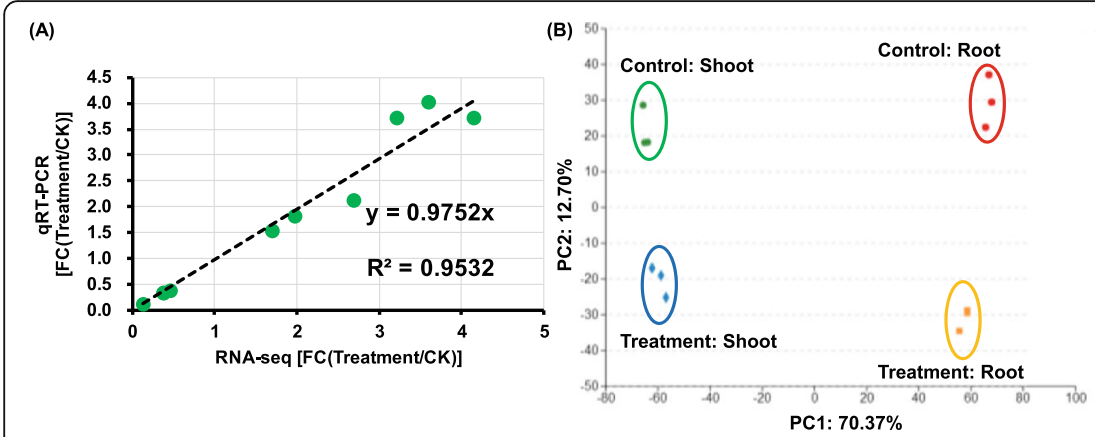

(C)

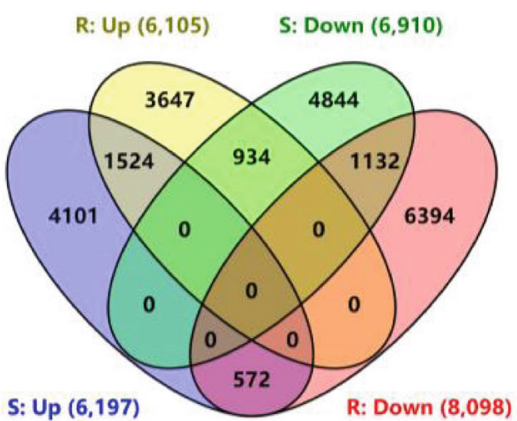

(D)

Shoot

Root
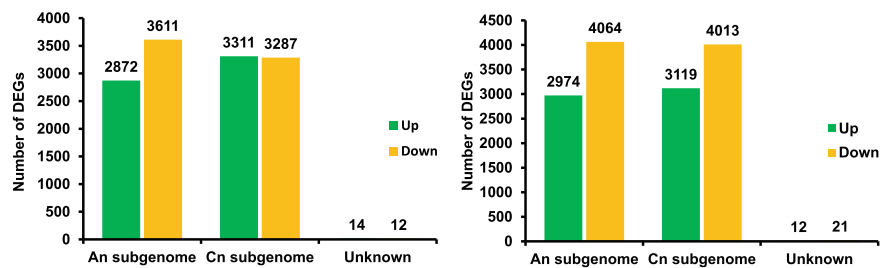

(F)

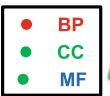

Detoxification Cell killing Macicromolecular complex Catalytic activity Response to stimulus

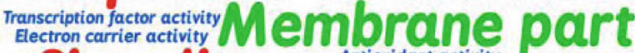
signaling Organanelle Cell junctiontransporter activity Growth

(G) Shoot

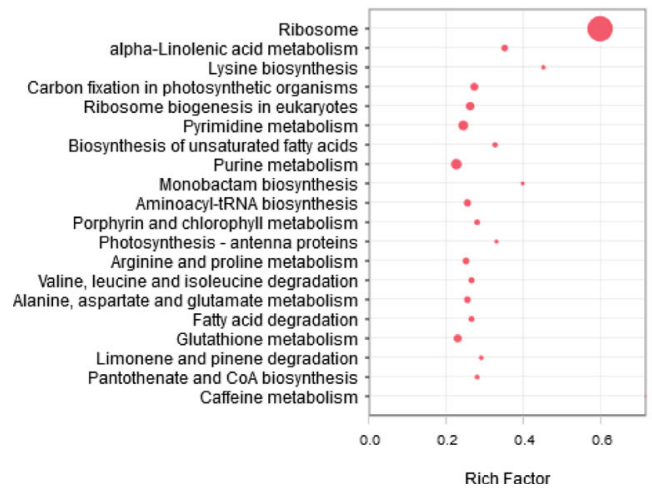

(G) Root

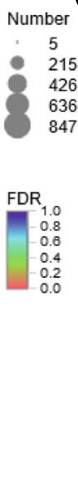

5
215
426

636

847

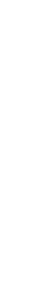

Phenylpropanoid biosynthesis
Plant-pathogen interaction Plant-pathogen interaction
Plant hormone signal transduction Plant hormone signal transduction -
Arginine and proline metabolism Tyalactose metabolism Limonene and pinene degradation
Cutin, suberine and wax biosynthesis Cutin, suberine and wax biosynthesis
Starch and sucrose metabolism Fatty acid elongation Glutathione metabolism Phenylalanine metabolism MAPK signaling pathway - plant Nitrogen metabolism

Ubiquinone and other terpenoid-quinone biosynthesis Fatty acid degradation Zeatin biosynthesis Isoquinoline alkaloid biosynthesis
golipid biosynthesis - ganglio series Glycosphingolipid biosynthesis - ganglio series

$$
\begin{array}{llllll}
0.0 & 0.1 & 0.2 & 0.3 & 0.4 & 0.5
\end{array}
$$

Rich Factor

Fig. 6 Overview of transcriptome sequencing data of rapeseed plants under the control and salt conditions. a Correlation analysis between the RT-qPCR assays and RNA-seq results. b, c Principal component analysis (B) and Venn diagram analysis (c) of the differentially expressed genes (DEGs) in the shoots (S) and roots (R) between the control and salt (treatment) conditions. The DEG numbers are listed in the brackets. $\mathbf{d}$-e Volcano diagrams showing the DEGs between the control and salt (treatment) conditions in the shoots (d) and roots (e). Up, upregulation; down, downregulation. $\mathbf{f}-\mathbf{g}$ GO (f) and KEGG pathway (g) enrichment analysis of global DEGs in the shoots and roots between the control and salt (treatment) conditions. For f, BP, biological process; CC, cellular component; MF, molecular function. Over-presentation of the GO items are delineated by the WordArt program. The bigger the font size, the more the corresponding GO categories. For $\mathbf{g}$, the circle size indicates the number of DEGs, and the rich factor indicates the degree of enrichment of KEGG pathways involving the DEGs. For the transcriptome sequencing, uniform rapeseed plants after 7-day seed germination were cultivated under $\mathrm{NaCl}$-free (control) for 10 days, and then they were changed to the solution containing $200 \mathrm{mM} \mathrm{NaCl}$ for $12 \mathrm{~h}$

than those on the An subgenome in both shoots and roots (Fig. 6d, e).

Before in-depth investigation of the specific responses of DEGs, molecular function (MF) of the DEGs showing the largest changes in the expression levels under salinity was explored. As shown in Table 1, the DEGs of late embryogenesis abundant (LEA) proteins, dehydrin, sugar and $\mathrm{N}$ transporters, defensins, and other stress-related proteins showed very high expression changes under salinity. Further, the enrichment analysis of GO terms, including MF, cellular component (CC), and biological process (BP), was performed to characterize main biological roles of the DEGs under salinity. In spite of the shoots or the roots under salinity, the most highly enriched GO term for BP was the response to stimuli, signaling, growth, and cell killing (Fig. 6f). However, the membrane part, organelle, and cell junction were the three most enriched items in the CC category (Fig. 6f). 
Table 1 Twenty differentially expressed genes with the highest expression changes under salinity in the shoots and roots

\begin{tabular}{|c|c|c|c|c|}
\hline & Gene ID & Fold change & Regulation & Annotation \\
\hline \multirow[t]{20}{*}{ Shoots } & BnaA02g07120D & 26,749 & Up & Non-specific lipid-transfer protein 4 \\
\hline & BnaA02g29990D & 14,762 & Up & Nitrile-specifier protein 5-like \\
\hline & BnaC09g48810D & 12,166 & Up & Late embryogenesis abundant protein 46 \\
\hline & BnaA10g20120D & 5989 & Up & Bidirectional sugar transporter SWEET15-like \\
\hline & BnaC02g45160D & 4650 & Up & Dehydrin Rab18-like \\
\hline & BnaA03g13140D & 4020 & Up & Non-specific lipid-transfer protein 3 \\
\hline & BnaC01g01500D & 3753 & Up & Cytochrome P450 81F1-like \\
\hline & BnaA10g24180D & 3753 & Up & Late embryogenesis abundant protein 46 \\
\hline & BnaC09g43920D & 3441 & Up & Bidirectional sugar transporter SWEET15-like \\
\hline & BnaC03g32950D & 3316 & Up & Stress-induced protein KIN2 \\
\hline & BnaA05g30910D & 0.0005 & Down & Response to water deprivation \\
\hline & BnaC04g33320D & 0.0015 & Down & Pentatricopeptide repeat-containing protein \\
\hline & BnaC03g01280D & 0.0015 & Down & Purine-uracil permease NCS1 \\
\hline & BnaC01g22240D & 0.0017 & Down & N-lysine methyltransferase \\
\hline & BnaA01g18330D & 0.0022 & Down & N-lysine methyltransferase \\
\hline & BnaA03g38630D & 0.0025 & Down & Pathogenesis-related protein 1-like \\
\hline & BnaA02g15510D & 0.0029 & Down & Endoglucanase 9-like \\
\hline & BnaC02g20750D & 0.0031 & Down & Endoglucanase 9-like \\
\hline & BnaC02g23620D & 0.0034 & Down & Defensin-like protein 3 \\
\hline & BnaC08g43380D & 0.0039 & Down & High-affinity nitrate transporter 2.1 \\
\hline \multirow[t]{20}{*}{ Roots } & BnaC03g32950D & 3947 & Up & Stress-induced protein KIN2 \\
\hline & BnaA10g24180D & 3304 & Up & Late embryogenesis abundant protein 46 \\
\hline & BnaC06g22120D & 2469 & Up & Defensin-like protein 3 \\
\hline & BnaCnng27850D & 1362 & Up & Dehydrin Rab18 \\
\hline & BnaA09g05190D & 1283 & Up & Bidirectional sugar transporter SWEET12 \\
\hline & BnaC05g41300D & 1115 & Up & Universal stress protein PHOS34-like \\
\hline & BnaCnng67820D & 1036 & Up & Sulfate transporter 3.1 \\
\hline & BnaC09g48810D & 939 & Up & Late embryogenesis abundant protein 46 \\
\hline & BnaC06g21150D & 937 & Up & Alcohol dehydrogenase class-P \\
\hline & BnaA09g49440D & 864 & Up & Protein phosphatase $2 \mathrm{C}$ \\
\hline & BnaA02g20580D & 0.0004 & Down & GDSL esterase/lipase \\
\hline & BnaC09g42600D & 0.0005 & Down & Senescence-associated carboxylesterase 101 \\
\hline & BnaA05g34160D & 0.0005 & Down & UDP-glycosyltransferase 83A1 \\
\hline & BnaA09g51570D & 0.0007 & Down & Cytochrome P450 78A6 \\
\hline & BnaC04g19370D & 0.0007 & Down & S-type anion channel SLAH1 \\
\hline & BnaC07g34090D & 0.0007 & Down & Protease \\
\hline & BnaA04g03090D & 0.0007 & Down & Glucan endo-1,3-beta-glucosidase \\
\hline & BnaC01g02200D & 0.0007 & Down & Protein RADIALIS-like 3 \\
\hline & BnaA03g35580D & 0.0007 & Down & Cytochrome P450 705A22-like \\
\hline & BnaC03g29930D & 0.0008 & Down & Cysteine-rich receptor-like protein kinase 37 \\
\hline
\end{tabular}

Note: down downregulation; up upregulation

In the MF annotation, the catalytic and transporter activities were the two most enriched items (Fig. 6f). The KEGG database was used to further identify the active pathways involving the responses of $B$. napus to salinity. In the shoots, the pathways for pyrimidine and purine metabolism, porphyrin and chlorophyll metabolism, and 
carbon fixation in photosynthetic organisms were highly enriched (Fig. 6g). In the roots, a large proportion of DEGs were mainly involved in the phenylpropanoid biosynthesis, plant hormone signal transduction, wax biosynthesis, and carbon (including starch and sugar)nitrogen metabolism (Fig. 6g).

\section{Transcriptional responses of photosynthesis and} anthocyanin biosynthesis-related genes to salinity Figure 3a-c shows the serious degradation of chlorophyll and the inhibition of photosynthesis in the rapeseed plants exposed to salinity. In the transcriptomic analysis, we found that chlorophyll biosynthesis-related genes, $\mathrm{Mg}^{2+}$ chelatase, senescence-associated genes (SAGs), and genes encoding photosynthesis II reaction proteins and $\mathrm{RuBisCo}$ subunit binding proteins were significantly down-regulated under salinity (Fig. 7a).

Anthocyanins, functioning as a kind of non-enzyme antioxidant against the stresses, are produced mainly in a phenylpropanoid-dependent manner. In the process of anthocyanin biosynthesis, first, phenylalanine is converted into cinnamic acid by phenylalanine ammonia lyase (PAL), and disintegrates into several pathways at coumaroyl CoA. Subsequently, coumaroyl CoA-deriving flavonoid is formed by the catalysis of chalcone synthase (CHS), which then triggers the biosynthesis of flavonol, cyanidin, and anthocyanin (Fig. 7b). In Fig. 3e, anthocyanins were found to be over-accumulated in the leaves of rapeseed plants after exposure to salinity. Further, transcriptional profiles of the genes involved in the anthocyanin biosynthesis were investigated under salinity. The results showed that about $95 \%$ of the DEGs were significantly up-regulated under salinity (Fig. 7b). The MYBbHLH-WDR (MBW) complex is critical for the anthocyanin biosynthesis [27]. A major proportion (75\%) of the genome-wide DEGs of BnaMYBs was found to be induced by salinity (Fig. 7c). The transcript levels of BnaA7.PAP1 and BnaA7.PAP2 were remarkably higher under salinity than under the control condition (Fig. $7 d$ ). Half $(50 \%)$ of the genome-wide DEGs of BnabHLHs were found to be induced by salinity (Fig. 7e). The two bHLH122 homologs (BnaA6.bHLH122 and BnaC6.bHLH122), significantly induced by salinity, showed the highest expression abundances (Fig. 7e, f). Only the differential expression of BnaA7.WD40 and BnaC7.WD40 was identified (Fig. 7g) in terms of the genome-wide $W D 40$ genes.

Transcriptional responses of genes involved in proline and cell wall biosynthesis, and ROS production and scavenging to salinity

Proline is a main osmotic adjustment substance to maintain cellular homeostasis under environmental stress [28]. Proline biosynthesis begins with the conversion of glutamate into glutamic semialdehyde by pyrroline-5carboxylate synthase (P5CS) or the conversion of ornithine into glutamic semialdehyde by ornithine aminotransferase (OAT), which is then converted into pyrroline-5-carboxylate reductase (P5CR), and, finally, into proline through the catalysis of OAT (Fig. 8a). Under salinity, proline was found to be overaccumulated; the expression of P5CS, OAT, and P5CR was significantly upregulated in both shoots and roots (Fig. 8a). On the contrary, the expression of BnaPDHs was significantly decreased (Fig. 8a). Among the DEGs that were involved in the proline biosynthesis, BnaA5.P5CS1, BnaC4.P5CS1a, BnaC7.OAT, BnaC9.P5CR, and BnaAn.PDH1, showing higher expression levels and fold changes (Fig. 8a), might be mainly responsible for the salinity-induced proline production.

In the morpho-physiologic analysis, significant alterations were found in the cell wall ultrastructure and components (Figs. 2, 4c). This study focused on pectin among the cell wall components. Pectin biosynthesis begins with UDP-glucuronates, which were then erased by UDP-glucuronates 4-epimerase, galacturonic transferase, and pectin methyltransferase (PMT), and, eventually, converted into pectin (Fig. 8b). The RNA-seq results showed that a larger proportion of the pectin biosynthesis-related genes were induced by salinity in the shoots or roots (Fig. 8b). Among these upregulated genes, BnaA2.GAUT14 and BnaC2.PMT, showing higher expression levels and fold changes (Fig. 8b), might play core roles in the pectin biosynthesis under salinity.

Respiratory burst oxidase homolog $(\mathrm{RBOH})$ genes encoding NADPH oxidases are pivotal for the ROS production [29]. All the eight $R B O H$ DEGs were significantly upregulated in the shoots or roots under salinity (Fig. 8c). In response to salinity, a larger proportion of the genes encoding SOD, CAT, and APX was upregulated in the shoots or roots (Fig. 8d). Among the antioxidant enzyme genes, BnaC8.SOD, BnaC6.CAT3, and BnaC7.APX6, showing higher expression levels and fold changes (Fig. 8d), might be essential for the ROS scavenging under salinity.

\section{Transcriptional responses of phytohormone biosynthesis- related genes to salinity}

The concentrations of IAA, CTK, and GA were markedly decreased and the concentrations of $\mathrm{ABA}$ and JA were obviously increased under salinity (Fig. 4b). Hence, the present study investigated transcriptional responses of the phytohormone metabolism-related genes to salinity in rapeseed.

Auxin biosynthesis begins with the conversion of tryptophan into indole-3-pyruvate, and finally into IAA, regulated by TAR2 and YUCCA (Fig. 9a). The principal auxin degradation pathways in Arabidopsis include 


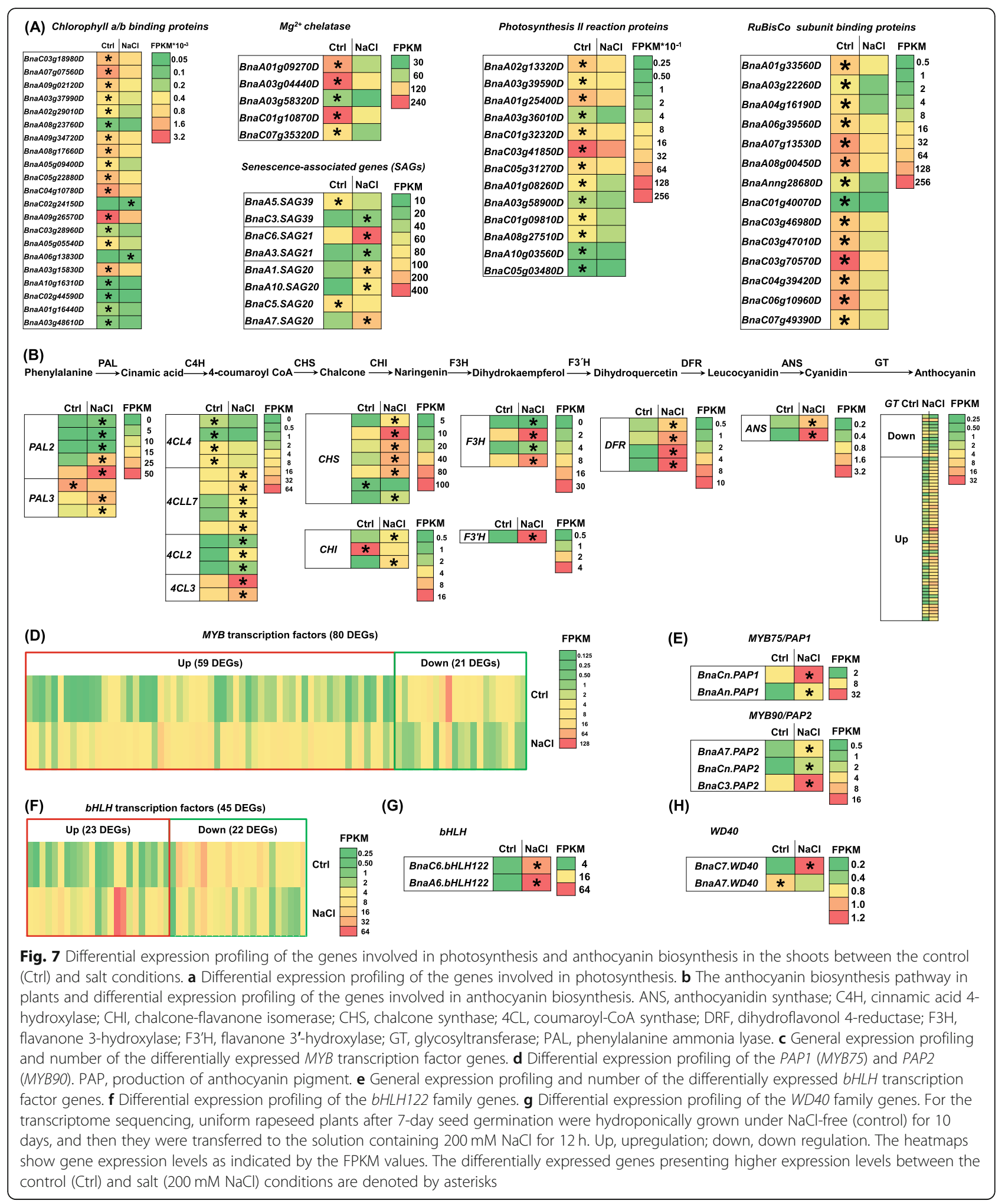

oxidation by dioxygenase for auxin oxidation and conjugation by Gretchen Hagen $3 s$ [30]. In general, the expression of BnaTAR2 was significantly downregulated under salinity, whereas the expression of BnaYUCCA was significantly up-regulated in the shoots and roots (Fig. 9a). Under salinity, most of the BnaDAO and $B n a G H 3$ DEGs were significantly up-regulated in the shoots and roots (Fig. 9a). CTK biosynthesis begins with 


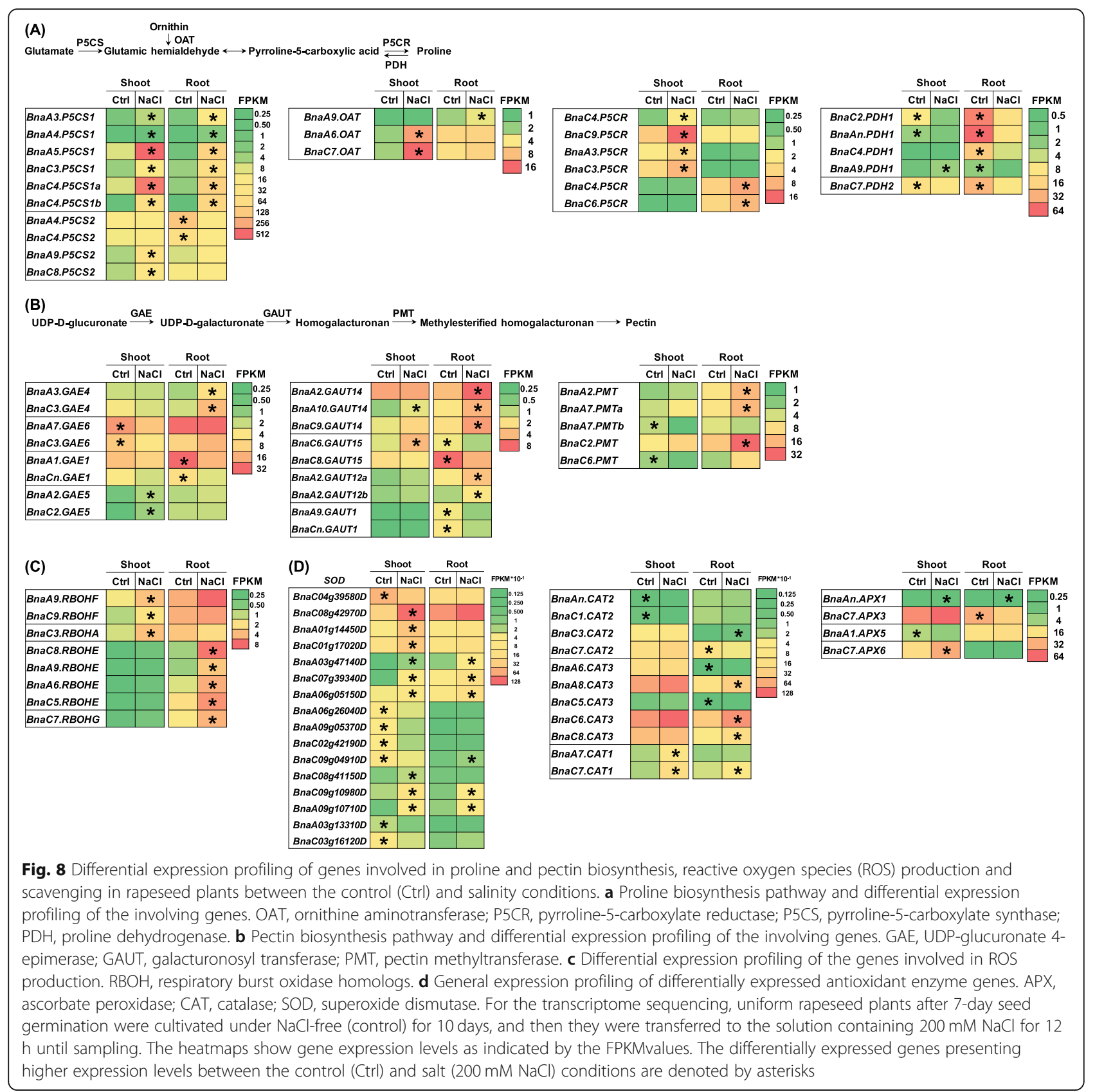

dimethylallyl diphosphate that finally is converted into active CTKs by IPT, CYP735A, and LOG. Under salinity, the expression levels of all the BnaIPT3 and BnaCYP735A1s and most BnaLOG DEGs were significantly down-regulated (Fig. 9b). GA biosynthesis begins with geranylgeranyl diphosphate that was converted into GA by CPS, KS, EKO, and GA 7-/13-/20-/3-/2-oxidases. Under salinity, the expression levels of BnaCPSs were significantly decreased, whereas the BnaEKOs were significantly up-regulated (Fig. 9c).

ABA biosynthesis begins with the conversion of $\beta$ carotene into ABA by a series of enzymes, such as ZEPs,
NSYs, NCEDs, and AAOs (Fig. 9d). Under salinity, the expression of BnaZEPs, BnaNSYs, BnaNCED2s, and BnaAAO3s were significantly up-regulated (Fig. 9d). The BnaC9.ZEP, BnaA9.NSY, and BnaA1.NCED3, showing higher expression levels and fold changes (Fig. 9d), might play dominant roles in the ABA biosynthesis. JA biosynthesis begins with the conversion of galactolipids into JA by a series of enzyme genes, include PLA 1 , LOX, AOS, AOC, OPR, and JAR1 (Fig. 9e). The JA biosynthesis-related genes showed a distinct transcriptional response to salinity. The DEGs of both BnaOPR3s and BnaAOSs were significantly up-regulated in the 


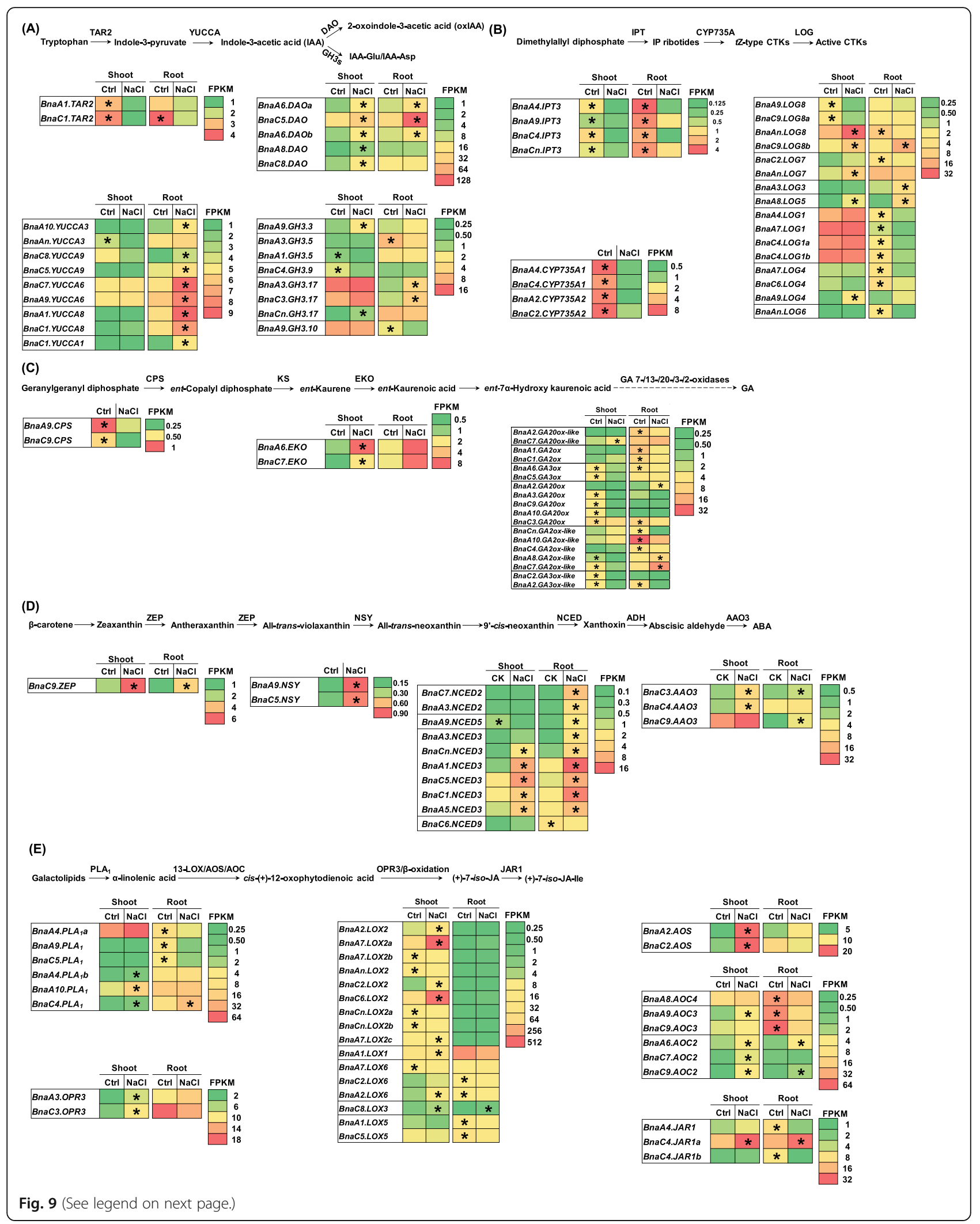


(See figure on previous page.)

Fig. 9 Differential expression profiling of genes involved in phytohormone biosynthesis in the rapeseed plants between the control (Ctrl) and salt conditions. a-e Biosynthesis pathways and differential expression profiling of the genes involved in auxin (IAA, a), cytokinin (CTK, b), gibberellin $(G A, \mathbf{c})$, abscisic acid (ABA, d), and jasmonic acid (JA, E). AAO, abscisic aldehyde oxidase; ADH, alcohol dehydrogenase; AOC, allene oxide cyclase; AOS, allene oxide synthase; CPS, ent-copalyl diphosphate SYNTHETASE; DAO, Dioxygenase for Auxin Oxidation; EKO, ent-kaurene 19-oxidase; GAox, GA oxidase; GH3s, Gretchen Hagen 3 s; KS, ent-kaurene synthase; LOX, lipoxygenase; NCED, 9-cis-epoxycarotenoid dioxygenase; OPR, 12-oxophytodienoic acid reductase; $P L A_{1}$, phospholipase $A_{1}$; ZEP, zeaxanthin epoxidase; ZSY, neoxanthin synthase. For the transcriptome sequencing, uniform rapeseed plants after 7-day seed germination were cultivated under $\mathrm{NaCl}$-free (control) for 10 days, and then they were transferred to the solution containing $200 \mathrm{mM} \mathrm{NaCl}$ for $12 \mathrm{~h}$. The heatmaps show gene expression levels as indicated by the FPKM values. The differentially expressed genes presenting higher expression levels between the control and $200 \mathrm{mM} \mathrm{NaCl}$ conditions are denoted by asterisks

rapeseed plants (Fig. 9e). However, other JA biosynthesis-related genes DEGs did not show consistent responses to salinity (Fig. 9e), implying a complex regulatory network of the JA biosynthesis under salinity. Among the DEGs, BnaA7.LOX2a, BnaC6.LOX2, BnaA2.AOS, BnaC2.AOS, and BnaC4.JAR1a showed enhanced expression levels and fold changes (Fig. 9e), and might play dominant roles in the JA biosynthesis.

\section{Transcriptional responses of $\mathrm{Na}^{+} / \mathrm{K}^{+}$transporter genes to salinity}

Among the numerous DEGs, much attention was paid to the genes implicated in nutrient ion homeostasis, which was crucial for the resistance of rapeseed plants to salinity. A molecular model showing the genes responsible for the transport of $\mathrm{Na}^{+}, \mathrm{K}^{+}$, and other cations was plotted in Fig. 10a. The transcriptomics results showed that most of the $\mathrm{K}^{+}$transporter genes, including the chloroplast-localized $\mathrm{K}^{+}$efflux transporter gene $K E A$ ( $K^{+}$efflux antiporter), the vacuolar $\mathrm{K}^{+}$influx transporter gene $K C O$ (two-pore $K^{+}$channel), the plasma membrane-localized $\mathrm{K}^{+}$influx transporter genes $A K T /$ KAT (Arabidopsis $K^{+}$transporter) and HKT (high-affinity $K^{+}$transporter type), and the $\mathrm{K}^{+}$efflux gene SKOR (stelar $\mathrm{K}^{+}$outward rectifier), were downregulated under salinity (Fig. 10b). The $\mathrm{Na}^{+} / \mathrm{H}^{+}$antiporter $(\mathrm{NHX})$ genes, particularly the tonoplast-localized $N H X 1$ and $N H X 2$ responsible for vacuolar $\mathrm{Na}^{+}$compartmentation and the plasma membrane-localized $S O S 1 / N H X 7$ regulating cell $\mathrm{Na}^{+}$extrusion, were upregulated (Fig. 10c). The downregulation of the chloroplast-localized bile acid sodium symporter (BASS) regulating $\mathrm{Na}^{+}$influx, particularly BnaA5.BASS2, and the upregulation of the NHD genes regulating $\mathrm{Na}^{+}$efflux, particularly BnaC3.NHD1 (Fig. 10c) might contribute to mitigating the chloroplast damages induced by excess $\mathrm{Na}^{+}$. Besides, excess $\mathrm{NaCl}$ also induced the expression of most of the ALMT (aluminum-activated malate transporter) genes involved in vacuolar chloride $\left(\mathrm{Cl}^{-}\right)$sequestration (Fig. 10c).

Subsequently, the expression of some other cation transporter genes, including cation calcium exchanger $(C C X)$, cation exchanger $(C A X)$, annexin $D(A N X D)$, glutamate-like receptor (GLR), and cyclic nucleotide-gated channel (CNGC) was investigated, which might be involved in the $\mathrm{Na}^{+}$homeostasis under salinity. Under salinity, the increased expression of BnaCCXs, the reduced expression of BnaCAXs, and the enhanced expression of BnaANXDs might contribute to diminishing the cytosolic $\mathrm{Na}^{+}$and enhancing cytosolic $\mathrm{Ca}^{2+}$ concentrations (Fig. 10d). Most of the expression of the plasma membrane-localized non-selective cation channels (NSCCs), including GLRs and CNGCs, was downregulated (Fig. 10d), which might prevent excess $\mathrm{Na}^{+}$ from entering the cytoplasm.

\section{Transcriptional response of other transporter genes to salinity}

Under salinity, $\mathrm{N}$ metabolism of plants was significantly changed [31]. A molecular model showed the genes involved in the $\mathrm{N}$ metabolism in plants (Fig. 11a). Under salinity, the nitrate transporter genes responsible for $\mathrm{N}$ uptake, including NRT1.1, NRT2.1, and NAR2.1, were significantly downregulated (Fig. 11a). Most of the vacuolar nitrate influx transporter genes, chloride channels $(C L C s)$, also showed decreased expression levels under salinity than under the control condition. The root nitrate xylem loading genes, BnaNRT1.5 $\mathrm{s}$, and root nitrate xylem unloading genes, BnaNRT1.8s, were upregulated and downregulated under salinity, respectively, contributing to a higher retention of nitrate in the roots against the salinity. The nitrate transporter genes responsible for $\mathrm{N}$ recycling from senescent leaves to new organs, NRT1.7 and NRT1.9, showed enhanced expression under salinity than under the control. In addition, the ammonium transporter genes, $A M T s$, were repressed by salinity. The nitrate reductase (NIA1 and NIA2) and nitrite reductase $(N I R)$ genes were downregulated, whereas the glutamine synthetase (GS) and glutamine-2-oxoglutarate aminotransferase (GOGAT) genes were induced by salinity.

Under salinity, most of phosphate (Pi) transporter genes were significantly down-regulated, especially BnaC9.PHT1;3c (Fig. 11b). Salinity obviously repressed the expression of B uptake channel genes, BnaNIP5;1s, and $\mathrm{B}$ transporter genes, BnaBOR1s and induced the expression of NIP6;1 s, boric acid channels for preferential transport of boron to growing shoot tissues (Fig. 11c). The transporter genes (including IRT1s, COPTs, and 


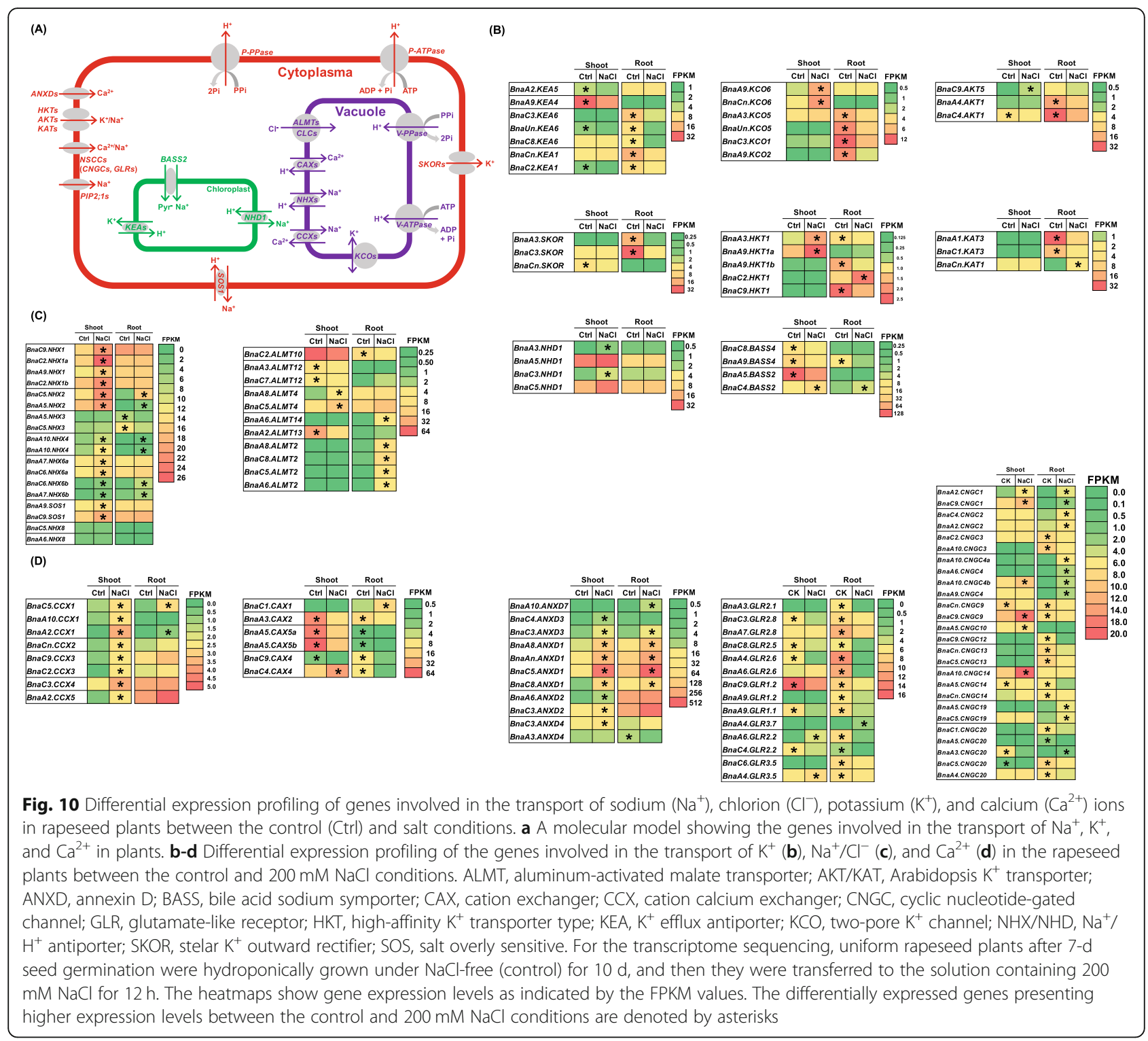

$M G T s)$ involved in the uptake and transport of $\mathrm{Fe}^{2+}$, $\mathrm{Cu}^{2+}$, and $\mathrm{Mg}^{2+}$ showed obvious downregulation in the roots under salinity (Fig. 11d-f). Under salinity, most of aquaporin genes, particularly BnaC4.PIP2;2b and BnaC2.TIP2;2, were significantly down-regulated in both the shoots and roots (Fig. 11f).

\section{Discussion}

Salinity conditions severely inhibit plant growth, yield, and crop quality worldwide. Allotetraploid rapeseed $\left(A_{n} A_{n} C_{n} C_{n}, 2 n=4 x=38\right)$, a major glycophytic oil crop, is highly susceptible to salinity. Understanding the physiological and molecular mechanisms underlying the rapeseed salinity resistance is a promising and costeffective strategy for developing highly salt-resistant rapeseed cultivars.
Transcriptomics-assisted dissection into morphophysiologic responses of rapeseed plants to salinity Different crops adapt to different ranges of salt concentrations, and different $\mathrm{NaCl}$ concentrations have different effects on plants [32-35]. $\mathrm{NaCl}$ concentrations of 0 $\mathrm{mM}, 50 \mathrm{mM}, 100 \mathrm{mM}, 150 \mathrm{mM}, 200 \mathrm{mM}$, and $250 \mathrm{mM}$ were used to treat the rapeseed plants in this study so as to select the $\mathrm{NaCl}$ concentrations suitable for studying rapeseed SSR. The rapeseed plants did not show obvious growth inhibition at the $\mathrm{NaCl}$ concentrations of $50 \mathrm{mM}$, $100 \mathrm{mM}$, and $150 \mathrm{mM}$ (Fig. 1a, b). However, the rapeseed seedlings showed excessive salt-induced plant damages with $250 \mathrm{mM} \mathrm{NaCl}$, including early senescent leaves, inhibited roots, and, finally, plant death (Fig. 1a, b), which was not suitable for the crop SSR study. Finally, the $\mathrm{NaCl}$ concentration suitable for studying 


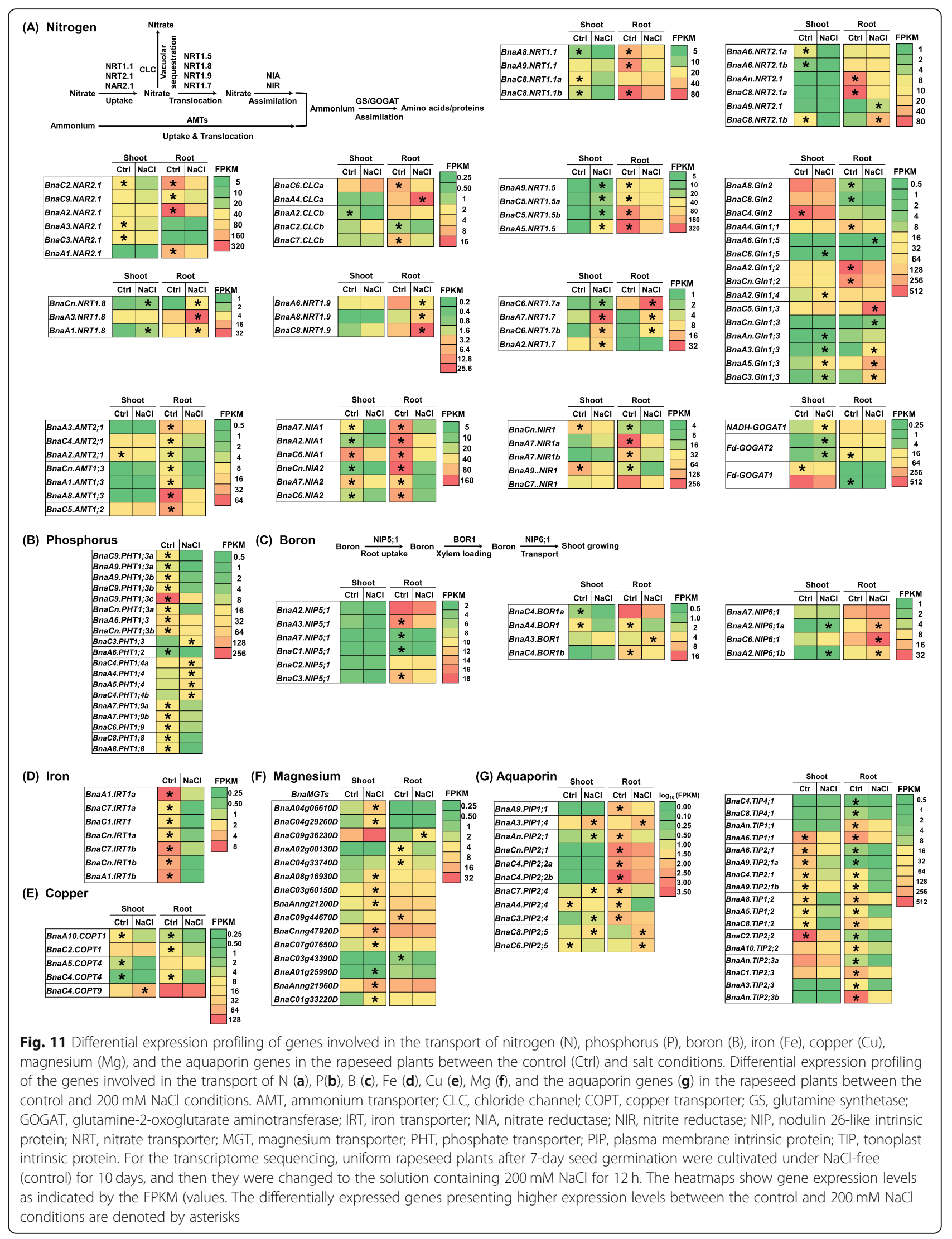


salinity of rapeseed was determined to be $200 \mathrm{mM}$, which was also widely used in other studies [35-39]. It might be concluded that $200 \mathrm{mM} \mathrm{NaCl}$ could be used as a universal condition for the crop SSR study under hydroponic culture.

Stomata, affected by environmental stimuli, is very important for the regulation of gas exchange between the leaf intracellular tissues and the external environment. A previous study shows that the stomatal valve also correlates with the net photosynthesis rate [40]. In this study, the salinity reduced the stoma number and conductance, and also resulted in the detached chloroplasts and chlorophyll degradation (Fig. 2), all of which might further lead to the photosynthesis inhibition (Fig. 3a-d). The transcriptomic data also showed that the photosynthesisrelated KEGG pathway was highly accumulated (Fig. 6g), and the genes involved in the chlorophyll biosynthesis pathway were significantly downregulated under salinity (Fig. 7a). As a functional index of the photosynthetic pigments and light adaptation [41], the concentration ratio of chlorophyll $a$ to chlorophyll $b$ was obviously higher under salinity than under the control condition (Fig. 3d), indicating that salinity had a more obvious inhibitory effect on chlorophyll $b$ than on chlorophyll $a$. In addition, the concentration ratio of total chlorophylls to carotenoids suggested the occurrence of senescence, stresses, or damages to photosynthesis [41], whereas salinity reduced the concentration ratio of total chlorophylls to carotenoids (Fig. $3 d$ ), indicating that chlorophylls were more sensitive to salt-induced damages.

Anthocyanins are important secondary metabolites and nonenzymatic antioxidants in plants [27]. Both the physiologic and transcriptomic data confirmed anthocyanin overaccumulation under salinity (Figs. 3e and b-g), which might protect the rapeseed leaves from excess photoinduced damages under salinity. Moreover, through a transcriptomic analysis, significant upregulation of some central genes that might be involved in the salinityinduced anthocyanin biosynthesis was identified, such as BnaCn.PAP1, BnaC3.PAP2, BnaA6.bHLH122, and BnaC7.WD40 (Fig. 7c-g). Previous studies showed that the osmotic modulator levels significantly changed under salinity [31]. Under salinity, soluble protein, proline, MDA, and soluble sugar concentrations significantly increased (Fig. 4a). However, no significant alteration of betaine was found under salinity in this study, which was different from previous findings $([31,42]$. This result indicated that betaine might not be involved in the osmotic regulation of rapeseed SSR.

Transcriptomics-assisted dissection into ionomic responses of rapeseed plants to salinity

Reducing $\mathrm{Na}^{+}$content and increasing $\mathrm{K}^{+}$content is key to improving plant salinity resistance. Under salinity, the
$\mathrm{Na}^{+} / \mathrm{K}^{+}$ratio significantly increased, affecting a variety of metabolic reactions in plants [43]. In this study, the $\mathrm{Na}^{+}$ concentration was found to be higher in the shoots than in the roots under salinity (Fig. 5d), which might further lead to a higher degree of biomass reduction in the shoots (Fig. 5h). The roots were first subjected to salinity, which had an enhanced inhibitory effect on the shoots than on the roots. The transcriptomic results showed that 13,107 and 14,203 DEGs were identified in the shoots and roots, respectively (Fig. 6c, d). The number of DEGs in the roots was obviously larger than that in the shoots, which might be attributed to the fact that the roots were first subjected to salinity.

In addition to reducing the cation concentration, the salinity condition caused an obvious decrease in the B concentration (Fig. 5), which was consistent with the downregulation of the B-uptake channel genes BnaNIP5; Is (Fig. 11c). Under salinity, the rapeseed leaves became much thicker, more curved, and fragile (Fig. 1a), which was similar to the symptoms caused by B deficiency in rapeseed plants [44]. Salinity also had a significant effect on the cell wall ultrastructure and components (mainly pectin) (Fig. 4c), relative water content [45], and aquaporin activities (Fig. 11), which were regulated by the B nutrient status [44]. In rapeseed, B deficiency was shown to aggravate the plant growth inhibition caused by salinity [46]. It was concluded that a close crosstalk might exist between B and salinity, and suitable exogenous B application might alleviate the salinity-induced damages in plants.

\section{Transcriptomics-assisted identification of core members of salinity-responsive gene families in rapeseed}

In this study, the morphological and physiological changes were identified in rapeseed plants under salinity condition (Figs. 1, 2, 3, 4 and 5). Further, through highresolution transcriptomics profiling, the central salinityresponsive genes that were involved in the biosynthesis of osmoregulatory substances, cell wall components, antioxidant enzymes, phytohormones and the transport of mineral nutrients were identified and characterized (Figs. 7, 8, 9, 10 and 11). Proline, a key osmoregulatory substance in plant salinity resistance, may participate in the regulation of phytohormone metabolism under short-term of salt stress [47]. Under salinity condition, the characterized core genes that were implicated in the proline biosynthesis, including BnaA5.P5CS1, BnaA7.OAT, BnaC9.P5CR, and BnaAn.PDH1 (Fig. 8a) would provide key genes for the molecular modulation of rapeseed salinity resistance. Under salt shock, three genes (BnaC08g42970D, BnaC6.CAT3, and BnaC7.APX6) encoding SOD, CAT, and APX (Fig. 8c), respectively were proposed to play core roles in the salinity-induced ROS scavenging, which contributed to 
relieving cell damages. Phytohormones, regulating plant development and modulates abiotic stress resistance [48], were significantly changed under salinity condition in this study (Fig. 9). NCED is a rate-limiting enzyme for the ABA biosynthesis, and OsNCED5 overexpression, increasing $\mathrm{ABA}$ levels, enhances tolerance to rice salt resistance [48]. In addition, JA enhances the potato plant resistance to salt stress in vitro [49]. In this study, several key NCED3 and JAR homologs, such as BnaA1.NCED3 and BnaC4.JAR1a, were identified to be core genes regulating the ABA and JA biosynthesis, respectively (Fig. 9), which would provide key genes for fine tuning of phytohormone homeostasis under salinity conditions. $\mathrm{Na}^{+} / \mathrm{K}^{+}$ homeostasis is essential for salt stress adaptation. NHXmediated compartmentation of $\mathrm{Na}^{+}$into vacuoles is critical for plant salt stress resistance [50]. In this study, BnaC2.NHX1a and BnaC9.SOS1, identified as the core genes regulating vacuolar $\mathrm{Na}^{+}$sequestration and $\mathrm{Na}^{+}$efflux (Fig. 10) respectively, were proposed to elite gene resources for maintaining $\mathrm{Na}^{+}$homeostasis. Taken together, transcriptomics-assisted identification and characterization of core members of salinity-responsive gene families will provide elite gene resources for genetic modification of rapeseed salinity stress resistance.

\section{Conclusions}

Under salinity, plants have evolved multifaceted adaptive strategies to cope with the detrimental damages [51]. On one hand, this study identified the morpho-physiologic and ionomic changes in the shoots and roots of rapeseed plants under salinity stress. On the other hand, this study ascertained the core genes, encoding antioxidant enzymes, phytohormones, nutrient transporters and other stress-responsive proteins, among their multicopy family members through the high-resolution expression profiling, which will provide elite and definite gene resources for the molecular breeding of salinity-resistant rapeseed germplasm.

\section{Methods}

\section{Growth conditions and salt treatments}

Considering the rapeseed cultivar of Zhongshuang 11 (a winter cultivar), having well-known information on genome sequences, is an elite genotype with high oil quality, seed production, and strong stress resistance [19], we used Zhongshuang 11 as the rapeseed lines studied in the following experiments. Rapeseed seedlings, which was originally obtained from Prof. Jin-yong Huang (jinyhuang@zzu.edu.cn, Zhengzhou University, Zhengzhou, 450,001, Henan Province, China), were hydroponically grown with Hoagland nutrient solution in an illuminated growth chamber [52]. The cultivated conditions were set according to the report by Hua et al. [52].
For the determination of morpho-physiologic parameters, uniform rapeseed plants after 7-day seed germination were grown under $\mathrm{NaCl}$-free (control) condition for 10 days. After that, the plants were changed to a solution containing $0-250 \mathrm{mM} \mathrm{NaCl}$ for 5 days until plant sampling. For the transcriptome sequencing, uniform rapeseed plants after 7-day seed germination were grown for $10 \mathrm{~d}$ under $\mathrm{NaCl}$-free condition, and then they were changed to the solution containing $200 \mathrm{mM} \mathrm{NaCl}$ for 12 $\mathrm{h}$ until sampling.

\section{Leaf and root system architecture analysis}

An LI-COR LI-3100C leaf area meter was used to determine total leaf areas of rapeseed plants. Specific leaf weight was used to assess leaf thickness, and was calculated according to the following equation: specific leaf weight $\left(\mathrm{g} \mathrm{FW} \mathrm{cm}^{-2}\right)=$ leaf FW (g) / leaf area $\left(\mathrm{cm}^{2}\right)$ [53].

Roots of rapeseed seedlings were subjected to an image scanner, and then total root length, root volume, root surface area, and root average diameter were analyzed using WinRHIZO Pro (Regent Instruments, QC, Canada).

\section{Photosynthesis-related parameter analysis}

A Li-Cor 6400 photosynthesis system was used to determine the following net photosynthetic rate $\left(P_{n}\right.$, $\mu \mathrm{mol}$ $\left.\mathrm{m}^{-2} \mathrm{~s}^{-1}\right)$, stomatal conductance $\left(g_{s}, \mathrm{~mol} \mathrm{H}_{2} \mathrm{O} \mathrm{m} \mathrm{m}^{-2} \mathrm{~s}^{-1}\right)$,

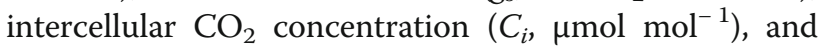
transpiration rate $\left(T_{r}, \mathrm{mmol} \mathrm{H}_{2} \mathrm{O} \mathrm{m}{ }^{-2} \mathrm{~s}^{-1}\right)$. The $P n, \mathrm{~g}_{s}$, $C_{i}$, and $T_{r}$ were measured at the following condition: photon intensity of $1300 \mu \mathrm{mol} \mathrm{m} \mathrm{m}^{-2} \mathrm{~s}^{-1}$, leaf temperature of $28.0 \pm 1.0^{\circ} \mathrm{C}$, relative humidity of $50.0 \% \pm 1 \%$, and atmospheric $\mathrm{CO}_{2}$ concentration of $400 \pm 5.0 \mathrm{mmol} \mathrm{mol}^{-1}$.

SPAD values of rapeseed leaves were determined using a SPAD-502 chlorophyll meter (Konica Minolta, Tokyo, Japan). Chlorophyll and carotenoid pigments were extracted using $80 \%$ isopropyl alcohol (v/v) for $24 \mathrm{~h}$ in dark, and then the concentration of purified extract was determined with a UV-1800 spectrophotometer (MAPA DA, Shanghai, China) at 663.2, 646.8, and $470 \mathrm{~nm}$. The anthocyanin was isolated using an isolation buffer $\left(\mathrm{CH}_{3} \mathrm{OH}: \mathrm{H}_{2} \mathrm{O}: \mathrm{H}_{2} \mathrm{O}_{2}=60: 13: 2, v / v / v\right)$. Subsequently, the concentration of the extract was determined with the UV-1800 spectrophotometer at 530 and $657 \mathrm{~nm}$.

\section{Microscopy analysis}

Pieces of rapeseed leaves of approximately $1 \mathrm{~mm}^{2}$ were taken to determine intracellular ultrastructures using a transmission electron microscope (H-7650; Hitachi, Tokyo, Japan) [54]. Stomatal density, morphology, and wax coat of the sampled leaf pieces was determined using a scanning electron microscope (JSM-6390/LV, JEOL, Tokyo, Japan) [55]. The leaf samples with at least 
three independent biological replicates were examined for electron microscopy analysis.

\section{Ionomic analysis}

Over-dried shoot and root tissues were added to a $\mathrm{HNO}_{3} /$ $\mathrm{HClO}_{4}$ mixture $(4: 1, \mathrm{v} / \mathrm{v})$ at $200{ }^{\circ} \mathrm{C}$ until the digestion was completed. The diluted supernatant was determined to quantify the concentrations of mineral elements using an inductively coupled plasma mass spectrometry (ICP-MS; NexIONTM 350X, PerkinElmer).

\section{Determination of osmoregulatory substances}

Concentrations of malondialdehyde (MDA), which was extracted using thiobarbituric acid, were spectrophotometrically assayed at the wavelengths of $450 \mathrm{~nm}, 532 \mathrm{~nm}$, and $600 \mathrm{~nm}$ [50]. Proline concentrations were determined at $520 \mathrm{~nm}$ with an ultraviolet spectrophotometer (UV-160, Shimadzu, Tokyo, Japan) using the ninhydrin assay [56].

Soluble protein concentrations were determined using the Bradford reagent, and the absorbance of the sample extract was determined at $595 \mathrm{~nm}$ [57]. Concentration of soluble sugars were determined in ethanol extract of rapeseed plants with the anthrone method [58]. Betaine was extracted using $0.375 \%(\mathrm{w} / \mathrm{v})$ Reinecke salt following the protocol described by [59], and the absorbance was read at $525 \mathrm{~nm}[60]$.

\section{Phytohormone assay}

Fresh rapeseed samples were prepared to obtain the phytohormone extract [61]. The standard auxin (indole-3acetic acid, IAA), cytokinin (CTK), gibberellin (GA), abscisic acid (ABA), and jasmonic acid (JA), and ABA were purchased from Sigma-Aldrich (St. Louis, MO, USA) or OlChemIm (OlChemIm, Olomouc, Czech Republic). The phytohormone concentrations were determined by ultra-fast liquid chromatography-electrospray ionization tandem mass spectrometry (UFLC-ESI-MS) [62].

\section{ROS determination and enzyme activity assay}

Fresh leaves and roots were harvested and immediately frozen. Potassium phosphate buffer $(\mathrm{pH} 7.8)$ and $0.1 \%$ (w/v) trichloroacetic acid were used to obtain the $\mathrm{O}_{2}{ }^{-}$ and $\mathrm{H}_{2} \mathrm{O}_{2}$ extracts, respectively. The absorbance of the aforementioned obtained extract was spectrophotometrically determined at the wavelengths of 530 and 390 $\mathrm{nm}$, respectively [63].

The SOD activity was spectrophotometrically determined at $560 \mathrm{~nm}$ using the nitroblue tetrazolium method [64]. The POD activity was spectrophotometrically assayed by monitoring the formation of guaiacol at 470 nm [65]. The CAT activity was calculated according to the study by Aebi [66]. The APX activity was assayed according to ascorbate oxidation at $290 \mathrm{~nm}$ [67].

\section{High-throughput transcriptome sequencing}

Rapeseed seedlings after 7-day seed germination were grown under $\mathrm{NaCl}$-free conditions for 10 days, and then were transferred to the nutrient solution to which was added to $200 \mathrm{mM} \mathrm{NaCl}$ for $12 \mathrm{~h}$ until sampling.

Shoots and roots of the rapeseed plants aforementioned were harvested, and three independent biological replicates were used for each treatment. Pre-chilled Trizol (Takara Bio Inc., Kusatsu, Shiga, Japan) was used to isolate total RNA, following which the RNA integrity number (RIN) was assessed. A total of 12 RNA samples with the RIN values $>8.0$ were obtained to construct strand-specific cDNA libraries, which were further employed for the paired-end sequencing (read length = $150 \mathrm{bp}$ ) on a lane of an Illumina Hiseq 4000 platform. The FPKM values were normalized to quantify the gene expression abundances, and both FDR and $P$ values < 0.05 were used to identify the differentially expressed genes (DEGs) [23]. PANTHER (http://www.pantherdb. org/data/) [68] and KEGG (http://www.kegg.jp/) [69], respectively, were used to perform GO and pathway enrichment analysis of the DEGs. Heat maps showing differential gene expression were delineated using a Multiexperiment Viewer (http://www.tm4.org/mev.html) [70].

\section{Reverse-transcription quantitative polymerase chain reaction assays}

Total RNA of each sample was extracted by using prechilled TRIzol reagent (Invitrogen, Carlsbad, CA, USA) according to the manufacturer's recommendations. After treating RNA samples with RNase-free DNase I, total RNA was used as templates for cDNA synthesis with the PrimeScript $^{\text {Tix }}$ reverse transcription (RT) Reagent Kit with gDNA Eraser (Perfect Real Time; TaKaRa, Shiga, Japan). To detect relative expression of target genes, RT-quantitative polymerase chain reaction (RT-qPCR) assays were conducted under an Applied Biosystems StepOne ${ }^{\text {Tw }}$ Plus system (Thermo Fisher Scientific, Waltham, MA, USA). The RT-qPCR program was set according to the following thermal cycles: $95^{\circ} \mathrm{C}$ for $3 \mathrm{~min}, 40$ cycles of $95^{\circ} \mathrm{C}$ for $10 \mathrm{~s}$, and $60^{\circ} \mathrm{C}$ for $30 \mathrm{~s}$. Expression levels of the target genes were normalized using two public house-keeping genes, BnaEF1- $\alpha$ [71] and BnaGDI1 [72], based on the $2^{-\Delta \Delta C}$ method [73]. The RT-qPCR primers used in this study are listed in Supplementary Table S1.

\section{Statistical analysis}

The Statistical Productions and Service Solutions 17.0 (SPSS, Chicago, IL, USA) was used to perform statistical testes. One-way analysis of variance followed by Tukey's honestly significant difference $(P<0.05, P<0.01$, and $P<0.001)$ multiple comparison tests was used to determine the significance differences. 


\section{Supplementary Information}

The online version contains supplementary material available at https://doi. org/10.1186/s12870-020-02734-4.

Additional file 1: Table S1.

Additional file 2: Supplementary Figure S1. Pearson correlation coefficients of the RNA-seq data between each pair of biological replicates. Note: C, control; T, treatment (200 mM NaCl); S, shoot; R, root.

\section{Abbreviations}

ABA: Abscisic acid; AKT: Arabidopsis $\mathrm{K}^{+}$transport system; AtKC1: Arabidopsis thaliana $\mathrm{K}^{+}$channel; APX: Ascorbate peroxidase; BASS: Bile acid: $\mathrm{Na}^{+}$

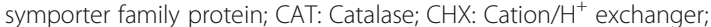
CNBD: Cyclic nucleotide binding domain; CPA: Cation/ $\mathrm{H}^{+}$antiporter; CTK: Cytokinin; DEG: Differentially expressed gene; GA: Gibberellic acid; GORK: Gated outwardly-rectifying K ${ }^{+}$channel; GS/GOGAT: Glutamine synthetase/glutamine oxoglutarate aminotransferase; HAK: High-affinity $\mathrm{K}^{+}$ transporter; IAA: Indoleacetic acid; JA: Jasmonic acid; KAT: $\mathrm{K}^{+}$channel in Arabidopsis thaliana; KEA: $\mathrm{K}^{+}$efflux antiporter; $\mathrm{KT}$ : $\mathrm{K}^{+}$transporter; KUP: $\mathrm{K}^{+}$ uptake transporter; MDA: Malondialdehyde; $\mathrm{NHX:} \mathrm{Na}^{+} / \mathrm{H}^{+}$exchanger; POD: Peroxidase; RT-qPCR: Reverse transcription quantitative polymerase chain reaction; SKOR: Stellar K+ outward rectifier; SOD: Superoxide dismutase; SOS: Salt overly sensitive

\section{Acknowledgements}

Not applicable.

\section{Authors' contributions}

HYP, ZT, and HJY was involved in data interpretation. CJQ and LY cultivated the rapeseed plants, and made the experiments. HJY and HYP designed the study, and HYP and FYN wrote the manuscript. All the authors read and approved the final version of the manuscript.

\section{Funding}

This study was financially supported by the National Natural Science Foundation of China (31801923 and U2004149), Major Collaborative Innovation Project of Zhengzhou (Key Discipline Construction Project of Zhengzhou University) (NO. xkzdjc201905), and Youth Innovation Project of Key discipline of Zhengzhou University (NO. XKZDQN202002).

\section{Availability of data and materials}

All the data and materials that are required to reproduce these findings can be shared by contacting the corresponding author. Dr. Ying-peng Hua (yingpenghua@zzu.edu.cn). The raw data of transcriptome sequencing have submitted to the National Centre for Biotechnology Information (NCBI) (http://www.ncbi.nlm.nih.gov/) with the Bioproject of PRJNA340053.

\section{Ethics approval and consent to participate}

In this study, all the seeds of rapeseed plants were obtained from our research group led by Prof. Jin-yong Huang (jinyhuang@zzu.edu.cn, Zhengzhou University, Zhengzhou, 450001, Henan Province, China).

\section{Consent for publication}

Not applicable.

\section{Competing interests}

The authors declare that they have no competing interests.

Received: 5 August 2020 Accepted: 9 November 2020

Published online: 24 November 2020

\section{References}

1. Munns R, Gilliham M. Salinity tolerance of crops-what is the cost? New Phytol. 2015;208:668-73.

2. Yang YQ, Guo Y. Elucidating the molecular mechanisms mediating plant salt-stress responses. New Phytol. 2018;217:523-39.

3. Smith P, House Jl, Bustamante M, et al. Global change pressures on soils from land use and management. Glob Chang Biol. 2016;22:1008-28.

4. Shabala S. Learning from halophytes: physiological basis and strategies to improve abiotic stress tolerance in crops. Ann Bot. 2016;112:1209-21.
5. Suzuki K, Yamaji N, Costa A, et al. OsHKT1;4-mediated $\mathrm{Na}(+)$ transport in stems contributes to $\mathrm{Na}(+)$ exclusion from leaf blades of rice at the reproductive growth stage upon salt stress. BMC Plant Biol. 2016;16:22.

6. Munns R, Tester M. Mechanisms of salinity tolerance. Annu Rev Plant Biol. 2008:59:651-81.

7. Raddatz N, Morales de Los Ríos L, Lindahl M, Quintero FJ, Pardo JM. Coordinated Transport of nitrate, potassium, and sodium. Front Plant Sci. 2020;11:247.

8. Zhang M, Cao Y, Wang Z, Wang ZQ, Shi J, Liang X, Song W, Chen Q, Lai J, Jiang C. A retrotransposon in an HKT1 family sodium transporter causes variation of leaf $\mathrm{Na}^{+}$exclusion and salt tolerance in maize. New Phytol. 2018:217:1161-76.

9. Chen XG, Lu XK, Shu N, Wang DL, Wang S, Wang JJ, Guo LX, Guo XN, Fan WL, Lin ZX, Ye WW. GhSOS1, a plasma membrane $\mathrm{Na}^{+} / \mathrm{H}+$ antiporter gene from upland cotton, enhances salt tolerance in transgenic Arabidopsis thaliana. PLoS One. 2017;12:e0181450.

10. Wu HH, Shabala L, Zhou M, Su N, Wu Q, Ul-Haq T, Zhu J, Mancuso S, Azzarello E, Shabala S. Root vacuolar $\mathrm{Na}^{+}$sequestration but not exclusion from uptake correlates with barley salt tolerance. Plant J. 2019;100:55-67.

11. Ward PR, Fillery IRP, Maharaj EA, Dunin FX. Water budgets and nutrients in a native Banksia woodland and an adjacent Medicago sativa pasture. Plant Soil. 2003;257:305-19.

12. Zhu JK. Plant salt tolerance. Trends Plant Sci. 2001;6:66-71.

13. Tester $\mathrm{M}$, Davenport R. $\mathrm{Na}^{+}$tolerance and $\mathrm{Na}^{+}$transport in higher plants. Ann Bot. 2003:91:503-27.

14. Wani SH, Kumar V, Khare T, et al. Engineering salinity tolerance in plants: progress and prospects. Planta. 2020;251:76

15. Blackshaw R, Johnson E, Gan YT, May W, McAndrew D, Barthet V, McDonald T, Wispinski D. Alternative oilseed crops for biodiesel feedstock on the Canadian prairies. Can J Plant Sci. 2011;91:889-96.

16. Wang XW, Wang HZ, Wang J, et al. The genome of the mesopolyploid crop species Brassica rapa. Nat Genet. 2011:43:1035-9.

17. Bayer PE, Hurgobin B, Golicz AA, et al. Assembly and comparison of two closely related Brassica napus genomes. Plant Biotechnol J. 2017;15: 1602-10.

18. Chalhoub B, Denoeud F, Liu S, et al. Plant genetics. Early allopolyploid evolution in the post-Neolithic Brassica napus oilseed genome. Science. 2014:345:950-3.

19. Sun F, Fan $G, H u$ Q, et al. The high-quality genome of Brassica napus cultivar 'ZS11' reveals the introgression history in semi-winter morphotype. Plant J. 2017;92:452-68.

20. Fang YJ, Li J, Jiang JJ, Geng YL, Wang JL, Wang YP. Physiological and epigenetic analyses of Brassica napus seed germination in response to salt stress. Acta Physiol Plant. 2017:39:128.

21. Arif MR, Islam MT, AHK R. Salinity stress alters root morphology and root hair traits in Brassica napus. Plants (Basel). 2019:8:192.

22. Mohamed IAA, Shalby N, Bai C, et al. Stomatal and photosynthetic traits are associated with investigating sodium chloride tolerance of Brassica napus L. cultivars. Plants (Basel). 2020;9:62

23. Wan HP, Chen LL, Guo JB, Li Q, Wen J, Yi B, Ma CZ, Tu JX, Fu TD, Shen JX. Genome-wide association study reveals the genetic architecture underlying salt tolerance-related traits in rapeseed (Brassica napus L.). Front Plant Sci. 2017:8:593.

24. Shokri-Gharelo R, Noparvar PM. Molecular response of canola to salt stress: insights on tolerance mechanisms. Peer J. 2018:6:e4822.

25. Xiong JL, Wang HC, Tan XY, Zhang CL, Naeem MS. 5-aminolevulinic acid improves salt tolerance mediated by regulation of tetrapyrrole and proline metabolism in Brassica napus L. seedlings under $\mathrm{NaCl}$ stress. Plant Physiol Biochem. 2018:124:88-99.

26. Demidchik V, Straltsova D, Medvedev SS, Pozhvanov GA, Sokolik A, Yurin V. Stress-induced electrolyte leakage: the role of Kt-permeable channels and involvement in programmed cell death and metabolic adjustment. J Exp Bot. 2004;65:1259-70.

27. Chaves-Silva S, Santos ALD, Chalfun-Júnior A, Zhao J, Peres LEP, Benedito VA. Understanding the genetic regulation of anthocyanin biosynthesis in plants-tools for breeding purple varieties of fruits and vegetables. Phytochemistry. 2018;153:11-27.

28. Liang XW, Zhang L, Natarajan SK, Becker DF. 2013. Proline mechanisms of stress survival. Antioxid. Redox Signal. 2013;19:998-1011. 
29. Kaya H, Takeda S, Kobayashi MJ, et al. Comparative analysis of the reactive oxygen species-producing enzymatic activity of Arabidopsis NADPH oxidases. Plant J. 2019;98:291-300.

30. Mellor N, Band LR, Pěnčík $A$, et al. Dynamic regulation of auxin oxidase and conjugating enzymes AtDAO1 and GH3 modulates auxin homeostasis. Proc Natl Acad Sci U S A. 2016;113:11022-7.

31. Liu L, Wang B, Liu D, Zou CL, Wu PR, Wang ZY, Wang YB, Li CF. Transcriptomic and metabolomic analyses reveal mechanisms of adaptation to salinity in which carbon and nitrogen metabolism is altered in sugar beet roots. BMC Plant Biol. 2020;20:138.

32. Krishnamurthy P, Vishal B, Khoo K, Rajappa S, Loh CS, Kumar PP. Expression of AoNHX1 increases salt tolerance of rice and Arabidopsis, and bHLH transcription factors regulate AtNHX1 and AtNHX6 in Arabidopsis. Plant Cell Rep. 2019;38:1299-315

33. Gao LM, Liu M, Wang M, Shen QR, Guo SW. Enhanced salt tolerance under nitrate nutrition is associated with apoplast $\mathrm{Na}^{+}$content in canola (Brassica napus L.) and rice (Oryza sativa L.) plants. Plant Cell Physiol. 2016;57:2323-33.

34. Jin T, Sun YY, Zhao RR, Shan Z, Gai JY, Li Y. Overexpression of peroxidase gene GsPRX9 confers salt tolerance in soybean. Int J Mol Sci. 2019;20:3745.

35. Bian XH, Li W, Niu CF, et al. A class B heat shock factor selected for during soybean domestication contributes to salt tolerance by promoting flavonoid biosynthesis. New Phytol. 2020;225:268-83.

36. Zhang HX, Blumwald E. Transgenic salt-tolerant tomato plants accumulate salt in foliage but not in fruit. Nat Biotechnol. 2001;19:765-8.

37. Wang M, Yuan JR, Qin LM, Shi WM, Xia GM, Liu SW. TaCYP81D5, one member in a wheat cytochrome P450 gene cluster, confers salinity tolerance via reactive oxygen species scavenging. Plant Biotechnol J. 2020;18:791-804.

38. Devkar V, Thirumalaikumar VP, Xue GP, Vallarino JG, Turečková V, Strnad M, Fernie AR, Hoefgen R, Mueller-Roeber B, Balazadeh S. Multifaceted regulatory function of tomato SITAF1 in the response to salinity stress. New Phytol. 2020;225:1681-98.

39. Park YC, Lim SD, Moon JC, Jang CS. A rice really interesting new gene H2type E3 ligase, OsSIRH2-14, enhances salinity tolerance via ubiquitin/26S proteasome-mediated degradation of salt-related proteins. Plant Cell Environ. 2019;42:3061-76.

40. Geng G, Lv C, Stevanato P, Li RR, Liu H, Yu LH, Wang YG. Transcriptome analysis of salt-sensitive and tolerant genotypes reveals salt-tolerance metabolic pathways in sugar beet. Int J Mol Sci. 2019;25:20.

41. Aman R, Carle R, Conrad J, Beifuss U, Schieber A. Isolation of carotenoids from plant materials and dietary supplements by high-speed countercurrent chromatography. J Chromatogr A. 2005;1074:99-105.

42. Soliman M, Elkelish A, Souad T, Alhaithloul H, Farooq M. Brassinosteroid seed priming with nitrogen supplementation improves salt tolerance in soybean. Physiol Mol Biol Plants. 2020;26:501-11.

43. Almeida DM, Oliveira MM, Saibo NJM. Regulation of $\mathrm{Na}^{+}$and $\mathrm{K}^{+}$ homeostasis in plants: towards improved salt stress tolerance in crop plants. Genet Mol Biol. 2017:40:326-45.

44. Hua YP, Zhou T, Ding GD, Yang QY, Shi L, Xu FS. Physiological, genomic and transcriptional diversity in responses to boron deficiency in rapeseed genotypes. J Exp Bot. 2016;67:5769-84.

45. García-Sánchez F, Simón-Grao S, Martínez-Nicolás JJ, Alfosea-Simón M, Liu CG Chatzissavvidis C, Perez-Perez JG, Cámara-Zapata JM. Multiple stresses occurring with boron toxicity and deficiency in plants. J Hazard Mater. 2020;397:122713.

46. Hosaini Y, Homaee M, Karimian NA, Saadat S. Modeling vegetative stage response of canola (Brassica napus L.) to combined salinity and boron stresses. Int J Plant Prod. 2009;3:91-104.

47. Zhu Y, Jiang X, Zhang J, He Y, Zhu X, Zhou X, Gong H, Yin J, Liu Y. Silicon confers cucumber resistance to salinity stress through regulation of proline and cytokinins. Plant Physiol Biochem. 2020;156:209-20.

48. Huang Y, Jiao Y, Xie N, Guo Y, Zhang F, Xiang Z, Wang R, Wang F, Gao Q, Tian L, Li D, Chen L, Liang M. OsNCED5, a 9-cis-epoxycarotenoid dioxygenase gene, regulates salt and water stress tolerance and leaf senescence in rice. Plant Sci. 2019;287:110188.

49. Efimova MV, Mukhamatdinova EA, Kovtun IS, Kabil FF, Medvedeva YV, Kuznetsov W. Jasmonic acid enhances the potato plant resistance to the salt stress in vitro. Dokl Biol Sci. 2019;488:149-52.

50. Kotula L, Garcia Caparros P, Zörb C, Colmer TD, Flowers TJ. Improving crop salt tolerance using transgenic approaches: An update and physiological analysis. Plant Cell Environ. 2020. https://doi.org/10.1111/pce.13865.

51. Hanin M, Ebel C, Ngom M, Laplaze L, Masmoudi K New insights on plant salt tolerance mechanisms and their potential use for breeding. Front Plant Sci. 2016;7:1787.
52. Hua YP, Feng YN, Zhou T, Xu FS. Genome-scale mRNA transcriptomic insights into the responses of oilseed rape (Brassica napus L.) to varying boron availabilities. Plant Soil. 2017;416:205-25.

53. Han S, Chen LS, Jiang HX, Smith BR, Yang LT, Xie CY. Boron deficiency decreases growth and photosynthesis, and increases starch and hexoses in leaves of citrus seedlings. J Plant Physiol. 2008;165:1331-41.

54. Ribeiro PG, Martins GC, Moreira CG, de Oliveira C, Andrade MLC, Sales TS, Chagas WFT, Labory CRG, de Carvalho TS, Guilherme LRG. Interactions of cadmium and zinc in high zinc tolerant native species Andropogon gayanus cultivated in hydroponics: growth endpoints, metal bioaccumulation, and ultrastructural analysis. Environ Sci Pollut Res Int. 2020. https://doi.org/10. 1007/s11356-020-10183-7.

55. Vandegeer RK, Zhao C, Cibils-Stewart X, Wuhrer R, Hall CR, Hartley SE, Tissue DT, Johnson SN. Silicon deposition on guard cells increases stomatal sensitivity as mediated by $\mathrm{K}^{+}$efflux and consequently reduces stomatal conductance. Physiol Plant. 2020. https://doi.org/10.1111/ppl.13202.

56. Deng S, Sun J, Zhao R, et al. Populus euphratica APYRASE2 enhances cold tolerance by modulating vesicular trafficking and extracellular ATP in Arabidopsis plants. Plant Physiol. 2015;169:530-48.

57. Bates LS, Waldren RP, Teare ID. Rapid determination of free proline for water-stress studies. Plant Soil. 1973;39:205-7.

58. Bradford MM. A rapid and sensitive method for the quantitation of microgram quantities of protein utilizing the principle of protein-dye binding. Anal Biochem. 1976;38:248-52.

59. Do BC, Dang TT, Berrin JG, Haltrich D, To KA, Sigoillot JC, Yamabhai M. Cloning, expression in Pichia pastoris, and characterization of a thermostable GH5 mannan endo-1,4-beta-mannosidase from Aspergillus niger BK01. Microb Cell Factories. 2009;8:59.

60. Grieve CM, Grattan SR. Rapid assay for determination of water soluble quaternary ammonium compounds. Plant Soil. 1983;70:303-7.

61. Yu JJ, Jin X, Sun XM, Gao TX, Chen XM, She YM, Jiang TB, Chen SX, Dai SJ. Hydrogen peroxide response in leaves of poplar (Populus simonii $\times$ Populus nigra) revealed from physiological and proteomic analyses. Int J Mol Sci. 2017;18:2085.

62. Liu HB, Li XH, Xiao JH, Wang SP. A convenient method for simultaneous quantification of multiple phytohormones and metabolites: application in study of rice-bacterium interaction. Plant Methods. 2012;8:2.

63. Zhou T, Hua Y, Huang YP, Ding GD, Shi L, Xu FS. Physiological and transcriptional analyses reveal differential phytohormone responses to boron deficiency in Brassica napus genotypes. Front Plant Sci. 2016;7:221.

64. Chu XT, Fu JJ, Sun YF, Xu YM, Miao YJ, Xu YF, Hu TM. Effect of arbuscular mycorrhizal fungi inoculation on cold stress-induced oxidative damage in leaves of Elymus nutans Griseb. S Afr J Bot. 2016;104:21-9.

65. Fu YY, Li FF, Xu T, Cai SJ, Chu WY, Qiu H, Sha S, Cheng GY, Xu QS. Bioaccumulation, subcellular, and molecular localization and damage to physiology and ultrastructure in Nymphoides peltata (Gmel.) O. Kuntze exposed to yttrium. Environ Sci Pollut Res. 2014;214:2935-42.

66. Aebi H. Catalase in vitro, vol. 105. New York: Academic; 1984

67. Nakano $Y$, Asada K. Hydrogen peroxide is scavenged by ascorbate-specifc peroxidase in spinach chloroplasts. Plant Cell Physiol. 1981;22:867-80.

68. Mi H, Lazareva-Ulitsky B, Loo R, et al. The PANTHER database of protein families, subfamilies, functions and pathways. Nucleic Acids Res. 2005;33:D284-8.

69. Kanehisa M, Araki M, Goto S, Hattori M, Hirakawa M, Itoh M, et al. KEGG for linking genomes to life and the environment. Nucleic Acids Res. 2008;36:D480-4.

70. Eisen MB, Spellman PT, Brown PO, Botstein D. Cluster analysis and display of genome-wide expression patterns. P Natl Acad Sci USA. 1998;95:14863-8.

71. Maillard A, Etienne P, Diquélou S, Trouverie J, Billard V, Yvin JC, Ourry A. Nutrient deficiencies in Brassica napus modify the ionomic composition of plant tissues: a focus on cross-talk between molybdenum and other nutrients. J Exp Bot. 2016;67:5631-41.

72. Yang HL, Liu J, Huang SM, Guo TT, Deng LB, Hua W. Selection and evaluation of novel reference genes for quantitative reverse transcription PCR (qRT-PCR) based on genome and transcriptome data in Brassica napus L. Gene. 2014;538:113-22.

73. Livak KJ, Schmittgen TD. Analysis of relative gene expression data using real-time quantitative PCR and the $2^{-\Delta \Delta C T}$ method. Methods. 2001;25:402-8.

\section{Publisher's Note}

Springer Nature remains neutral with regard to jurisdictional claims in published maps and institutional affiliations. 